\title{
Ki te taumata: a personal journey into the multiple identities of academically high achieving Māori girls
}

\author{
Liana MacDonald
}

A three paper thesis

submitted to the Victoria University of Wellington

in partial fulfilment of the requirements for the degree of

Masters in Education

Victoria University of Wellington 


\begin{abstract}
This thesis investigates the multiple identities of four academically high achieving, Māori girls negotiated in one English Medium mainstream schooling environment. The study sought to determine how these young women have grown to define and develop diverse understandings of what it means to "be Māori” and "high achieving” within this context.
\end{abstract}

The metaphor of plotting a path from the foothills to the peak of a mountain is used to describe the journey that the participants of this study, and I as a researcher, undertook during this process. Participating in this journey were 13 travellers; four academically high achieving Māori girls, four caregivers and four of the girls' friends. I also identify myself as a Māori female researcher as a traveller since I tell a story that has attempted to be transparent and personal. This case study was guided by Kaupapa Māori research protocols (Smith, 1999; Bishop \& Glynn, 2003) and Personal Experience methodology (Clandinin \& Connelly, 1994). Such protocols were useful in enabling me to tell this research story.

However, this was not the research journey I expected to take when I first set off. Through this inquiry process I learned about the influence of society and colonisation on the construction of identity. I learned how pressures and stereotypes, aligned with socialisation processes, lie beneath our consciousness and inform our individual and collective identities. The conversations with fellow participants of the study highlight the limitations in our understanding of what it means to be Māori and achieve educational success “as Māori” amongst contemporary youth today.

The findings of this study suggest that multiple complex Māori identities exist amongst contemporary Māori youth. Further research and discussion about what it means to "be Māori" needs to occur to ensure that we cater for the needs of all Māori learners. Recommendations include establishing a professional development programme for teachers to address the way knowledge is constructed and perpetuated in a contemporary, postcolonial society. A focus on motivation, gender, indigeneity and special/gifted abilities was not investigated in this thesis. 


\section{Acknowledgements}

First, I would like to thank the research participants of this study for their involvement in making this research journey possible. I would like to express sincere gratitude for their willingness to share their stories with me and the honesty with which they did so. Thanks also to the patience they afforded me when I would pop back into their lives with further questions, or thoughts about the direction of this research. Being privy to the personal stories of these exceptional Māori and Pākehā people was a humbling experience.

The support and guidance of my supervisor, Dr. Anne Hynds, has been fundamental to the completion of this thesis. While attempting (not always successfully) to juggle my study with the commitments of a full time job, she has been patient, positive and encouraging. She has enabled me to see the direction of this thesis during many stages of the research process and kept me moving along the trail. Ngā mihi nui ki a koe.

I would like to acknowledge the help of Andrea Milligan, a lecturer from Victoria University of Wellington's School of Education Policy and Implementation and a friend, who provided important feedback in the closing stages of writing this thesis. Thank you also to Dr. Vivien Van Rij who helped to edit the final draft.

Although I have found it hard to articulate this study to my friends and whānau, they have always been understanding and supportive of my drive to conduct this research. Finally, many thanks to the secondary school for allowing me to conduct the research within this environment and to those staff members who conveyed their support. 


\section{CONTENTS}

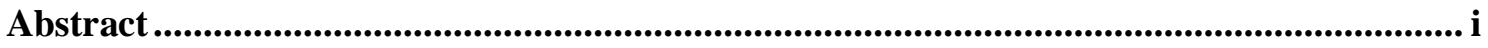

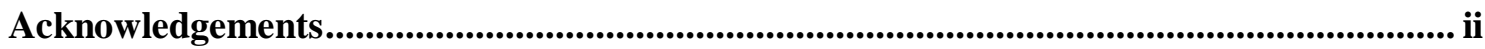

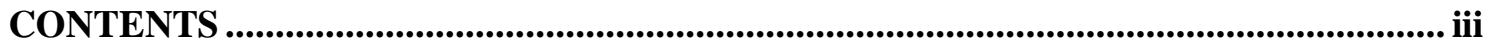

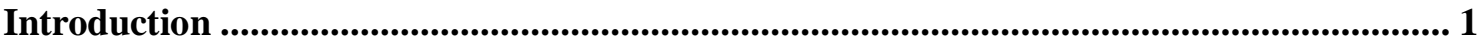

CHAPTER 1 At the Foothills: Preparing for the Journey...................................................... 3

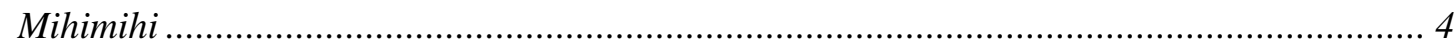

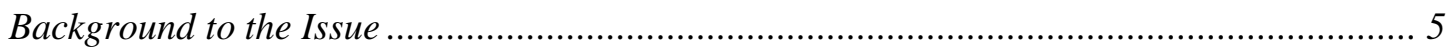

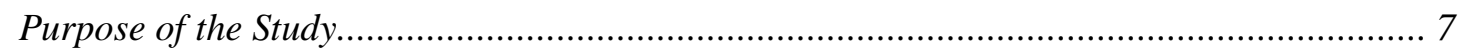

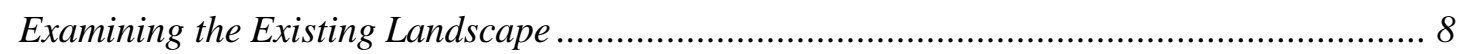

Literature concerning high achieving or giftedness in Māori education ............................11

Research studies that used the voices of high achieving or gifted students .......................13

Māori homogeneity within Māori research...................................................................14

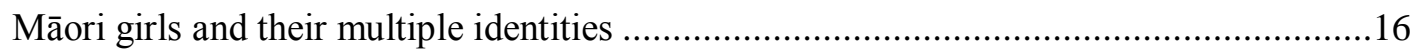

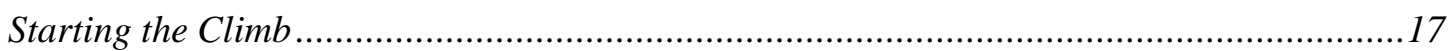

CHAPTER 2 Plotting a Path that is Transparent and Personal........................................18

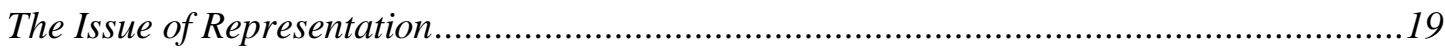

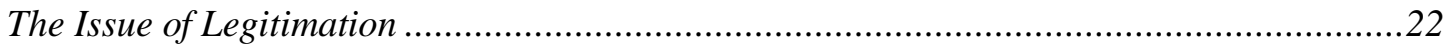

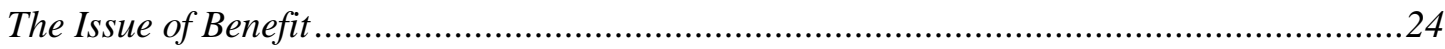

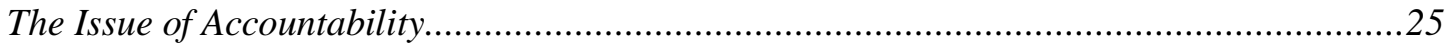

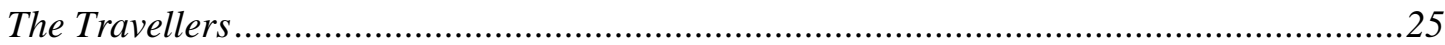

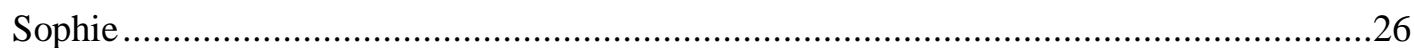

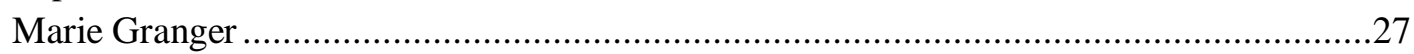

Lea Williams

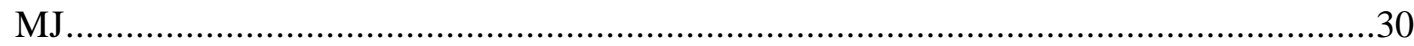

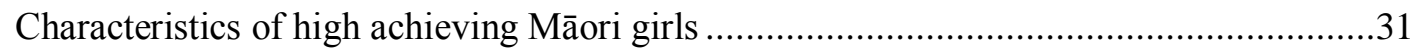

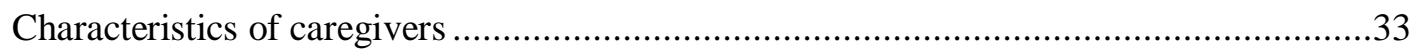

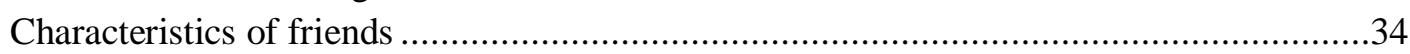

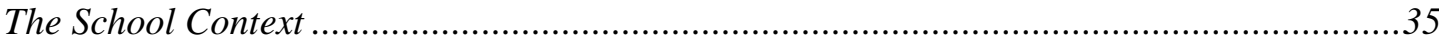

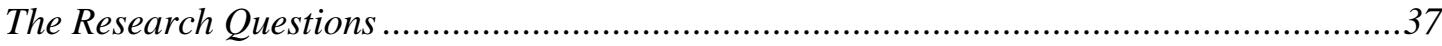

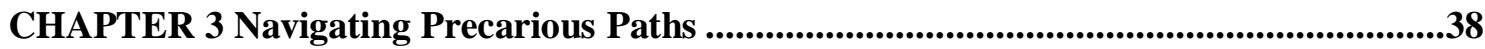

Fixed or Traditional Māori Identities: The Established Route...............................................39

1. Affirmation of traditional Māori identity markers at school ....................................39

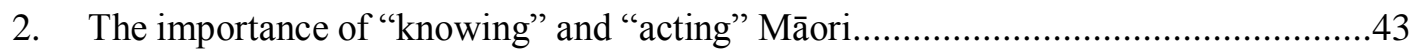

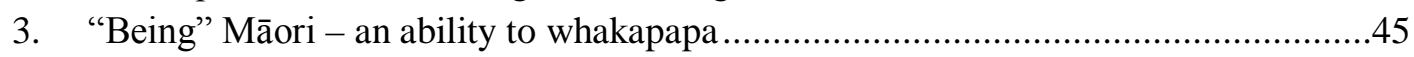

Forced Identities: The Unmapped Trail .......................................................................46

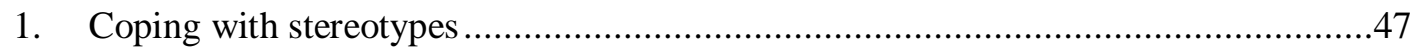




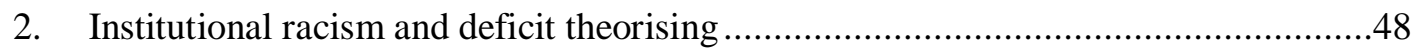

3. "Being” Māori, "looking” Pākehā ........................................................................50

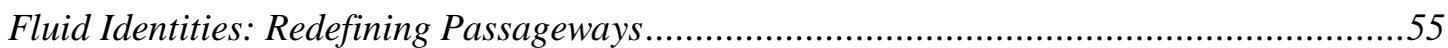

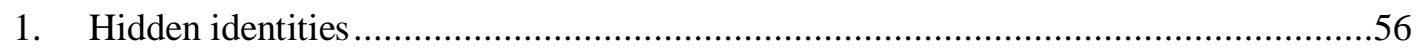

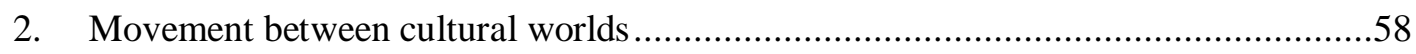

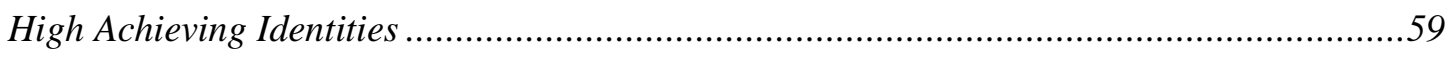

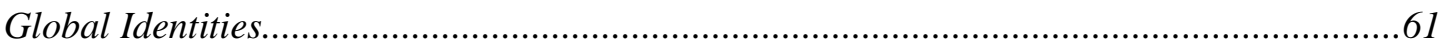

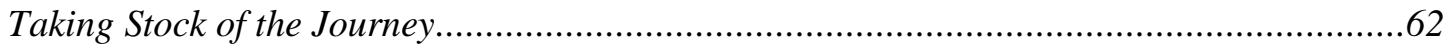

CHAPTER 4 Transcending the Clouds.................................................................................64

Postcolonial Theory and the Construction of Knowledge ....................................................64

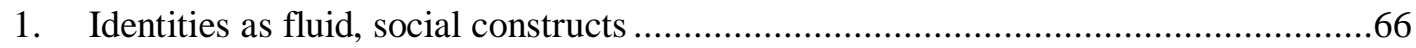

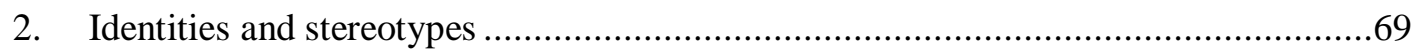

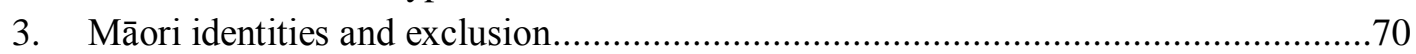

4. The tension between Māori identities and high achieving identities .........................72

The Challenge and Complexity of Researching Identity ......................................................75

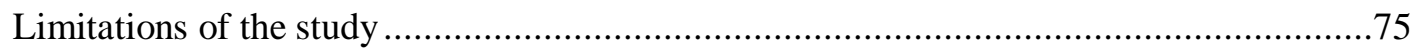

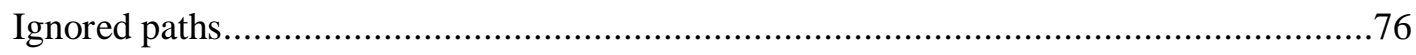

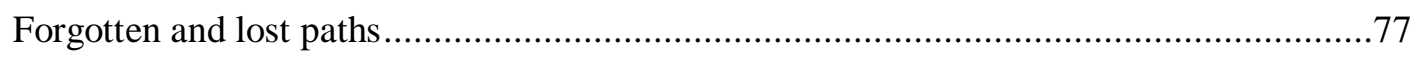

In Pursuit of the Summit: Recommendations for Researchers, Policymakers and Practice. ..79

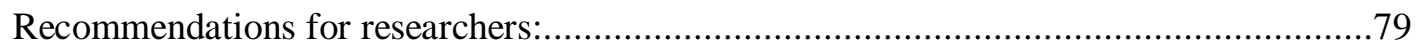

Recommendations for policymakers: Ministry of Education ...........................................79

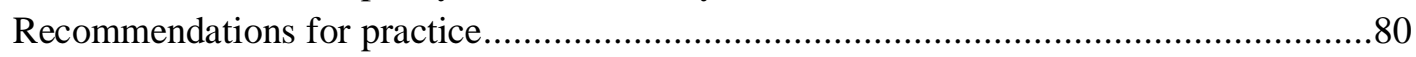

Māori Girls and their Multiple Identities: A Call to Continue the Journey ...........................82

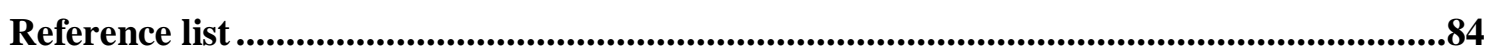

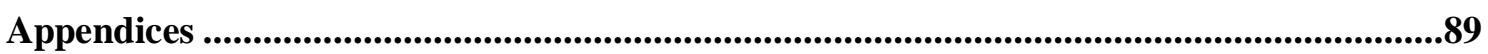

Appendix A: Relationships between Research Participants ...............................................89

Appendix B: Research Participation Information sheet and Consent form............................90

Appendix C: Follow up Letter to Participants......................................................................94

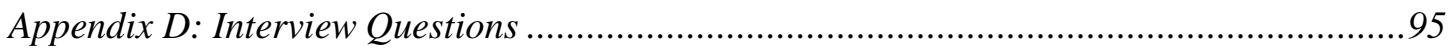




\section{Introduction}

Different research paths ki te taumata (to the peak) are relayed within the narrative of this thesis. The majority are based on the experiences of the participants in this study and one is based on my own. I believe it is apt that a research study which has attempted to delve into issues of personal identity acknowledges the perspectives from which this story is told. No story would come to fruition without a storyteller and similarly, the account which is about to unfold does so through the subjective lens of myself as researcher. I have used narrative inquiry to tell the "story" (Clandinin \& Connelly, 1994) of the multiple identities of four academically high achieving, Māori girls and through doing so, undergo a journey that reflects my personal and professional learning. Kaupapa Māori methodology guided my interactions with participants.

Chapter 1 introduces the reader to the metaphor of a climbing a mountain, which I have used throughout the thesis. I consider the ascent within the context of a much larger mountain range - the current climate of English Medium Māori education - by evaluating the existing terrain. This study has focussed on English Medium mainstream education, which is a learning context in which the language of instruction is English. A literature review helped to guide the preliminary paths I took on this research journey by revealing a dearth of research on academic high achievement and multiple identities of Māori students. I then traverse the foothills by recounting the initial stages of my research, which involved establishing, re-evaluating and re-establishing a research focus, before I attempt to venture, with unsure footing, onto the next stage.

In Chapter 2 I introduce the other 12 travellers and the schooling context in which the high achieving, Māori girls moved. I describe the path that I sought to take with those with whom I journeyed with. Kaupapa Māori and Personal Experience methodologies guided the research processes, as I endeavoured to follow a path that was transparent and personal.

Chapter 3 highlights the multiple identities and tensions experienced by the high achieving Māori girls that were made visible to me by their participation in this study. It was at this stage of the journey that the climb became most precarious as the complexities involved in researching identity began to take shape. I found myself stumbling over rough terrain and later realised that this was through trying to detect the paths that the girls had taken to reach academic success. Some of these trails were hidden from both the girls and myself since pressures and stereotypes were influencing participants’ perceptions. 
In Chapter $4 \mathrm{I}$ find that the summit is still out of reach. I arrive at some realisations about the complexities involved in researching identity that help me understand that the summit may be an unattainable goal. I discover that the multiple identities and tensions experienced by the high achieving, Māori girls in relation to their academic success can be attributed to postcolonialism and it is within this landscape that all students in Aotearoa must travel. I suggest that teachers engage in a professional development programme to learn about the inequities perpetuated by postcolonialism, including the construction of knowledge. The experiences of the high achieving, Māori girls of this study demonstrate that there are many way to "be Māori” in our society and subsequent research, practice and policy should take this into account. 


\section{CHAPTER 1}

\section{At the Foothills: Preparing for the Journey}

There's so many pathways to the top of the mountain, isn't there? I'm a real believer that everybody's journey looks different and the influences are different, so therefore the priorities and how you get there are going to look different. (Jane, Lea's Mother)

I have used this quotation from an interview in this study to allude to the nature of the journey of its participants and as a representation of the personal and professional journey that I experienced. I have come to realise that the account which is about to unfold is a partial story of my learning to date based on conversations with others. Each chapter of this thesis corresponds with a significant stage in the research journey and describes the many highs and lows that I experienced. The metaphor of climbing a mountain also provides a context for describing the navigations of four high achieving, ${ }^{1}$ Māori girls through a mainstream education schooling system. This study acknowledges the academic success of each of these girls, and the fact that their personal identities have contributed to their success. This journey ki te taumata, to the peak of the mountain, has not been without pitfalls for a large proportion of Māori students or these young women. While their academic success has remained constant, multiple identities - especially those related to their Māori culture and achievement exist simultaneously but in various states. The challenges presented within the Māori girls’ educational context have been significant. I therefore compare their experiences to climbing a mountain. Indeed, the girls have been discriminated against in two ways, first as female, and second as Māori. This study celebrates their educational success and journey to the top. This thesis invites discussion about the legitimacy of these students "enjoying education success as Māori”" who have and are succeeding in a mainstream educational context.

\footnotetext{
${ }^{1}$ For the purposes of this research I define "high achieving” and "academically successful” as the attainment of a NCEA level 1 or 2 certificate with a Merit or Excellence endorsement in 2009.

2 'Māori enjoying education success as Māori' is from MOE document Ka Hikitia (2009). I will return to this statement later in the chapter.
} 


\section{Mihimihi}

I consider myself a Māori New Zealander, who at the same time equally acknowledges my identity as a Pākehā New Zealander. I was raised by a Pākehā mother, who became a solo-parent after my father was killed in a car accident when I was very young. As a girl and a young woman, I would visit my whānau from my Father’s side (Ngāti Kuia, Ngāti Koata, Rangitāne) during the school holidays. I was close to my cousins and I suppose I was engaged in doing things Māori or following Māori ways, although on reflection I don't remember discerning a difference in lifestyle from what I was used to. I just enjoyed being with my family.

I was educated through an English Medium mainstream schooling system with little opportunity and (at the time) desire to learn about Māoritanga. I existed and flourished within this system because I knew how to play along with the rules of a school that only acknowledged a Pākehā way of doing things. As a student of Māori descent, I did not feel as though I had to adapt culturally to fit in and I didn't really see myself as different to other students who were predominantly Pākehā. Perhaps my upbringing helped me to develop an intrinsic understanding of the values and morals of the dominant, colonial culture and this allowed me to move freely within this environment. However, most of my Māori peers struggled to identify with the mainstream school culture and academic achievement, and most left school before the final senior year. As I moved through the schooling system (as fate would have it I became a teacher) I wondered at the way Māori students existed in English Medium mainstream schooling environments which seemed to be more openly bi-lingual and encouraging of their individual ethnic diversity than mine ever were. At each of the three schools I have taught at, it seemed to me that many Māori students who realised academic success did not have to compromise their Māori identity in the process. But, like my own schooling experience, the number of Māori attaining academic success appeared to be disproportionate to the number of Māori students at the school.

This research study has become a deeply personal journey for me. Throughout my life, I have had difficulty fitting easily into either a Pākehā, or a Māori world; at times able to move comfortably in both, I never quite felt as though I had my feet firmly planted in one or the other. During the interviews with the high achieving, Māori girls of this study, I have seen aspects of my own, sometimes fractious, journey within the English Medium mainstream education system mirrored back to me. It has been hard not to get emotionally involved with the data because their story is in some ways my story. The use of personal narrative is appropriate because it enables me to 
acknowledge outright such biases as I bring to the focus of this study and convey how participants' experiences have altered my way of thinking.

Therefore, my motivation to explore Māori girls’ multiple identities is grounded in personal experience, which has led me to believe that making claims based on identity and ethnicity is far more complicated than current research suggests. Observations as a professional who has worked closely with Māori students in different school environments have enabled me to see that when the issue is academic achievement in a mainstream schooling environment, community and social contexts really do matter.

\section{Background to the Issue}

Before I begin this story, it is essential that I acknowledge the climate in which the participants of this study and I have travelled. The mountain we climbed was within the context of a much larger social, political and economical mountain range; one that began with the colonisation process inflicted on Māori society by the English in the nineteenth century. Penetito (2010) describes this process as "acts of separation... from traditional lands, language, cosmologies, economies, sources of power and authority, knowledge and customs, food supplies and much more” (p. 37) which he suggests have led to problems of identity. During the early stages of this research, I was aware that colonialism had impacted indigenous communities negatively and that these historical “acts of separation” led to the disparity in achievement between Māori and Pākehā students in education. My experiences of working with Māori students in schools have shown me how hard educators work towards rectifying this, with little tangible result.

It is difficult to have a conversation about Māori and mainstream education without acknowledging the Māori “underachievement problem” that exists within English Medium primary and secondary schools. Academics have theorised this issue and debated the causes and solutions of it for decades (Walker, 1991; Bishop, 1999; Bishop \& Glynn, 2003; Bishop \& Berryman, 2006; Bishop, Berryman, Cavanagh \& Teddy, 2009). In 2007, statistics showed that only 60 percent of Māori students were meeting National Certificate of Educational Achievement (NCEA) level 1 literacy and numeracy requirements, whereas these requirements were met by nearly 80 percent of non-Māori. In that same year, 44 percent of Māori were leaving school with NCEA level 2 or above, however the figure for non-Māori was 71 percent. $^{3}$

\footnotetext{
${ }^{3}$ Data taken from http://www.educationcounts.govt.nz/statistics/Māori education/13182/36805
} 
The persisting problem of low Māori achievement in mainstream schools is at the forefront of Ministry of Education research and initiatives, such as Te Kotahitanga (Bishop et al., 2009), Te Kauhua (Bull, n.d.) and Ka Hikitia (Ministry of Education, 2009). Two divergent philosophies are currently circulating that discuss the reasons behind this problem. Both signal barriers faced by Māori students in English Medium mainstreams institutions that result from the colonisation process, so can be viewed as postcolonial perspectives. The first is the influence of deficit thinking amongst mainstream teachers and the low expectations they have of Māori students to perform academically, thereby making it hard for Māori to succeed. Proponents of this theory have argued that "culture counts" and that part of the solution resides in combating the dominance of Pākehā culture in mainstream schools and classrooms (Bishop \& Glynn, 2003; Macfarlane, 2004). Bishop et al. (2009) introduced an Effective Teaching Profile (ETP) which contains culturally responsive pedagogies that have been shown to be conducive to Māori achieving in English Medium mainstream schooling environments. The ETP states, among other things, that teachers should be able to create culturally appropriate and responsive contexts for learning in their classroom and care for their students "as Māori”. An alternative argument maintains that it is the unequal access to resources that is the primary cause of the achievement disparity (Nash, 2001; Thrupp, 2007). Students from families with low socio-economic status (SES) will be more disadvantaged in schools because they lack the necessary economic resources needed for a successful schooling experience (Nash, 2001). Supporters of this theory believe that the disproportionately high number of Māori students who come from low SES households do not have the same kind of academic support that their non-Māori peers have access to. It is argued that constant research on the achievement disparity between indigenous and non-indigenous (who make up the dominant group) amounts to institutionalised racism because it causes low expectations, which in turn create a self fulfilling prophesy that impacts on student motivation (Sheilds, Bishop \& Mazawi, 2005).

I believe that both of these theories, whilst developed to address the Māori underachievement problem, are actually working from a deficit perspective. A key question that plagued me as I read through the literature was what about Māori students who are succeeding academically in a mainstream schooling environment: something must be working for them and if so, what?

It is within this context that arguably the most significant document addressing this disparity enters. Ka Hikitia - Managing for Success: The Māori Education Strategy 
(hereafter referred to as Ka Hikitia) clearly states its aim: "In this strategy, 'Māori enjoying education success as Māori' means having an education system that provides all Māori learners with the opportunity to get what they require to realise their own unique potential and succeed in their lives as Māori. Succeeding as Māori captures and reflects that identity and culture are essential ingredients of success” (Ka Hikitia, 2009, p.18). How each school should facilitate the stated goals and actions to meet the needs of all Māori learners and provide successful outcomes within their particular educational context is determined by separate schools as is what it means for schools' students to succeed in their lives as Māori. The second focus area of the strategy, 'Young people engaged in learning', states that targets to achieve success as Māori include increased NCEA academic outcomes, better retention rates of Māori students, increased numbers of young Māori moving towards tertiary study, and retention within these fields (pp. 32-33).

Early on in the research process, I knew this document would play a significant role in the telling of my story. However, it was not until the participants began sharing their stories that I realised to what extent. I would have to experience rough terrain that the high achieving, Māori girls had experienced before I really began to question the superficial assumptions that documents such as Ka Hikitia made.

\section{Purpose of the Study}

This study has enabled me to critique Māori education from the perspective of one who has never felt as though my voice and experiences were acknowledged as valid within this discourse. A research focus on multiple Māori identities in English medium mainstream schooling institutions has legitimised something I have always intuitively known was missing in discussion about Māori achievement and success. My hope is that policymakers, teachers and researchers concerned with Māori education will acknowledge those students whose Māori identities are hidden, fluid, lost, forced and those that have yet to be named, also have a legitimate voice. 


\section{Examining the Existing Landscape}

The theoretical framework for conducting this research was influenced by social constructivism. Social constructivists believe that knowledge is not constructed "in isolation but against a backdrop of shared understandings, practices, language and so forth” (Schwandt, 2000, p. 197). The knowledge constructed from this body of work has developed through my interactions with the participants. Gergen (1994a) in Schwandt (2000) states: "It is human interchange that gives language its capacity to mean, and it must stand as the critical locus of concern” (p. 198). Similarly, in chapters 3 and 4 I demonstrate new learning and understandings about the issues of inquiry through the narratives of others. Clear links between this theoretical framework and the methodologies I have adopted will be discussed in the next chapter.

The initial focus of my research study was the exploration of the schooling experiences of "high achieving, middle class Māori” secondary students. My interest in this area stemmed from a Masters Research paper I had written during a course in Māori Education. The readings I had undertaken showed me that in contemporary literature a narrow viewpoint of what constitutes the Māori middle class existed. Based as it was on historical perspectives of Māori involved in treaty settlements and iwi capitalisation (Boraman, 2005; Poata-Smith, 2008; Rata, 2004). A magazine article from North \& South (Courtney, 2008) challenged my understanding of the concept of middle class by suggesting that for Māori it could be the ability to operate in both Māori and Pākehā worlds, as opposed to the European definition which cites economic independence as a measurement of class. The paper led me to conclude that further qualitative research that introduces social class as a factor that can influence educational achievement is needed in Māori Education discourse.

The research paper also stimulated my interest in finding out more about the kinds of social diversity that exist within Māori society. The readings had highlighted the dangers of disguising the socio-economic problems of Māori through identity politics (Boraman, 2005; Nash, 2001; Poata-Smith, 2008; Rata, 2004; Thrupp, 2007). Boraman (2005), Poata-Smith (2008) and Rata (2004) argue that a class struggle between Māori began with the inception of the Tino Rangatiratanga movement in the 1960s. Identity politics promoted a unified, homogenous Māori identity as a political tool, to combat racist policies and discrimination. Two wings of protest developed amongst Māori during this time; one was middle class dominated and wanted concessions from the state through legalistic activity, the other was flax roots-based, directly opposed to the state and focussed on direct action to achieve its aims. Rata 
(2004) believes that middle class Māori took economic advantage of the political conditions that identity politics offered: "The main argument used by neotribalists [middle class Māori] is that the traditional tribe still exists. The acceptance of this argument by biculturalists has enabled the neotribes to claim ownership of economic resources as tribal property and to claim the political status of Treaty of Waitangi partner” (Rata, 2004, p. 21). Rata goes on to discuss how neotribalism ${ }^{4}$ entrenches social inequality amongst Māori and that it creates false conditions that do not allow people to challenge their socio-economic conditions: "Explaining identity politics as middle class repositioning gives a different picture of what biculturalism was actually about” (Rata, 2004, 21). This helped me understand that arguments existed which pointed to the limitations and potentially harmful effects in the promotion of homogeneous social identity. I realised that it was more convenient for the government to be held accountable to iwi through the Treaty of Waitangi, than addressing the problem of making real social change for all Māori at the bottom of the socio-economic scale.

Another area of interest that was raised by this research paper was the need to find out more about the stories of Māori who are succeeding in this current political, social and economic climate. I had identified a lack of literature and research surrounding Māori middle class; Māori in society who had found economic success. It seemed logical that successful schooling experiences were probably precursors to eventual financial security; therefore, I believed that a story based around students who were academically successful in English Medium mainstream schools would reflect this. The eventual decision to focus on Māori girls became a purely pragmatic one since the school that became the focus for this research did not have enough Māori boys who were academically high achieving, according to the previously defined NCEA standards.

In order to find out more about the schooling experiences of high achieving, middle class Māori secondary students, I reviewed the current research literature through the Victoria University of Wellington databases using the constructs of high achieving or giftedness, middle class and Māori girls (and other related terms). I knew that finding a research context that would incorporate all of these constructs would be

\footnotetext{
4 "The model of neotribal capitalism refers to the articulation of the neotribal capitalist economy and the neotraditionalist ideology of kinship relations. Claims that this new social structure is the revived traditional tribal structure has enabled the neotribal elite to control the interpretation of the Treaty of Waitangi, concepts of indigeneity and customary rights, and to claim material resources, political power and leadership status.” (Rata, 2004, p. 15)
} 
unlikely; however I did not anticipate how little research had been done on each of these constructs. Several factors led me to refine my research focus and abandon a specific focus on class analysis. First, my search did not uncover any research about middle class Māori within education. Hence, I realised that the scope and limitations of my three-paper thesis would not be able to address the need to research this area thoroughly. Second, I realised that I was personally and professionally committed to a path that explored Māori achievement and I did not need to incorporate an analysis of social hierarchies to do this.

I began to think about the facets of schooling experience that I wanted to delve into more deeply and formed several questions: What contributed to Māori girls' academic success in current English Medium mainstream schooling environments? Did the students have to lose or adapt elements of their identity to become academically high achieving as was indicated through my experiences at school? My own schooling experiences and social interactions with Māori and Pākehā had given me an intrinsic understanding that identity was not a fixed construct. I saw how a focus on multiple Māori identities would enable me to counter Māori homogeneity and uncover social diversity in the process. As I began reading literature in these areas, I realised how my own study could contribute to the wider research base of published scholarship.

A focus on multiple Māori identities has led me to deepen my understanding of postcolonial theory. This has helped me to realise that in order to truly cater to the needs of Māori students in English medium mainstream schooling environments, policymakers, researcher and practioners must acknowledge that there are different ways of "being Māori ”. I previously introduced two MOE initiatives that are touted as helping to address the achievement disparity between Māori and Pākehā students in English Medium mainstream schools, Te Kotahitanga and Ka Hikitia. While they help to support a postcolonial point of view, they could be viewed as perpetuating the status quo by virtue of ignoring the complexities in identity that are created by the postcolonial condition. But before I go on any further, I must start from the beginning to tell my story properly.

The literature review I undertook for my research proposal became the literature review for this thesis. I located thirteen studies that were closely connected to the keywords of my focus. I had included the construct middle class as an element that the studies covered and this tied in with the interests of my current question and argument. An analysis of this literature indicated gaps existing within current research that 
ultimately legitimise my research project. The following section highlights my initial analysis of this literature.

\section{Literature concerning high achieving or giftedness in Māori education}

I found one article and three research studies that have focussed on high achievement and giftedness in education. Mahuika (2007) provides a comprehensive overview of literature relating to Māori and gifted education, surveying the relevant research up to that point. She states that "this review has identified several gaps in the research that must be addressed in order to engage the 'strengths and aspirations of Māori' in developing alternative structures and processes for the education and development of gifted and talented Māori students” (Mahuika, 2007, p. 9). She cites Bevan-Brown’s research (1993) as a foundational research study that, since its inception, has not been improved upon or thoroughly developed by other researchers or theorists.

Mahuika (2007) describes Bevan-Brown's (1993) qualitative research as an attempt to define a traditional and contemporary Māori concept of special abilities. It also discusses ways in which Māori people believe their Māori children with special abilities are best identified and catered for (Mahuika, 2007, p. 3). Mahuika (2007) introduces the case study of Jenkins, Moltzen and MacFarlane (2004) who discuss the facilitation of programmes and structures relevant to the advancement of Māori gifted and talented education (Mahuika, 2007, p .9). The research of Jenkins et al. (2004) supported Bevan-Brown's findings about Māori styles of leadership and their concepts of giftedness - both of which are different to a Eurocentric understanding. Her observations of whakahihi and whakaiti challenge the notion of how Māori viewed gifted students at that time. Bevan-Brown (1993) claims that Māori students are comfortable being open about their gifts within a safe whānau context, whereas previous to her study, academics believed that it was not a cultural characteristic for Māori to acknowledge giftedness in any form (Jenkins et al., 2004, p.64). While Jenkins et al. (2004) and Bevan-Brown (1993) present findings that "may be considered appropriate for many gifted Māori learners who identify themselves as Māori and adhere to their Māoritanga" (Bevan-Brown, 2004, p. 172 cited in Mahuika, 2007, p.9), there appear to be many limitations within each study.

Jenkins et al. (2004) does not use student voice in their discussion of how the school facilitated programmes for high achievement, so the reader must make do with the views expressed primarily by those facilitating the programme. Nor do Jenkins et al. (2004) and Bevan Brown (1993) make reference to academic attainment that would 
help to show that this programme was beneficial to alternative forms of gifted, or high achieving Māori outside of Bevan-Brown’s construct of Māori giftedness. They argue that a mainstream Māori gifted construct remains fundamentally Eurocentric in orientation. However, I thought it was realistic to expect that Māori students could be measured by both Māori and English concepts of giftedness.

In her research, Bevan-Brown (1993) acknowledges from the outset "that Māori, like any other culture, are a diverse group of people” (p. 4) but she cannot claim, from a study of 33 participants, that her findings are indicative of this. Jenkins et al. (2004) base their research findings on an area of low socio-economic resources in an area of South Auckland, but the claims they make are assumed typical of all Māori in the country. It seems to me to be completely inadequate to accept concepts of Māori special abilities or giftedness based on a research study of 33 participants conducted over 15 years ago and still expect them to be completely relevant in today's society. Yet current research suggests we do this - without considering the role that other social factors might play in determining high achievement.

An American researcher, Piirto (2002), adopted a qualitative, case study portraiture approach to a traditional Indian school in order to demonstrate how another culture's perspective of intelligence and giftedness is nurtured within an indigenous environment. Many schools in India are still governed in terms of a British influence, and reflect a society whose indigenous population has also been affected by the colonisation process. Piirto conducted her research within a school that based its education systems on indigenous philosophies. The students were described as “...poor, bright Indian children” who were taught spiritual and social development, as well as intellectual development. The school conveyed a clear understanding of cultural giftedness, which was closely linked to their students developing a social conscience that would make them want to contribute to making their society a better place.

The terms to describe the Indian students who attended the school are used interchangeably in Piirto's article. Terms such as bright, intellectually and spiritually strong, talented and gifted are understood as being the same construct of giftedness. In Bevan-Brown's foundational study on gifted Māori students (1993) the term special abilities becomes in a later discussion on the subject cultural giftedness (Bevan-Brown, 2005) and that term is picked up by Jenkins et al. (2004). However, there does not appear to be a consistent understanding of what these terms mean.

The Piirto study reaffirmed to me that in New Zealand we do not have a firm philosophical idea of what constitutes Māori giftedness to guide our schools. Although 
research and literature has discussed the concept of Māori giftedness, I could not find any literature that introduced the issue of mainstream academic high achievement for Māori students. Mahuika's literature review (2007) focussed on gifted education to critique how the "strengths and aspirations of Māori” (p. 9) were being met. This statement from Mahuika reminded me of Ka Hikitia's catchphrase "Māori achieving education success as Māori”, so I began to wonder how Ka Hikitia was being delivered in secondary schools if the notion of Māori gifted and talented and high achievement was an ambiguous concept in academic literature. Ka Hikitia delivers wide ranging suggestions of what constitutes Māori success and how this can be measured, but I did not find any reference to what Mahuika (2007), Jenkins et al. (2004) and Bevan-Brown (1993) has suggested were attributes of Māori giftedness. I also felt that Ka Hikitia set low expectations for many Māori students. I understood that there was an underachievement problem that needed immediate attention and that increasing retention rates and decreasing truancy statistics were vital in ensuring this would happen, but I did not feel that the document incorporated a holistic view of "education success as Māori”. I did not think that Ka Hikitia considered education success as viewed through the eyes of academically successful Māori students.

\section{Research studies that used the voices of high achieving or gifted students}

I located three case studies from the United States of America and New Zealand that use the student voice to inform their discussion about the indigenous students' schooling experiences. The terms high achieving, or gifted, in conjunction with indigenous and research yielded one qualitative case study from the United States of America (Grantham, 2003). By incorporating the words Māori and achievement I discovered two New Zealand studies that relied heavily on student voice. There were by Bishop et al. (2009) and Macfarlane (2004).

The American case study focuses on Rocky Jones, a gifted black student (Grantham, 2003) and asks questions about his academic experiences that considered how all of his day-to-day relationships affected his academic outcomes. All social considerations (home, peers, teachers and other school factors) were taken into account while the researcher builds a picture of Rocky's academic success. The two qualitative studies from New Zealand (Bishop et al., 2009; Macfarlane, 2004) use similar interview-type techniques, but focus solely on the academic experiences of Māori within a school environment, with most of the impetus being on those students most disaffected or disengaged from learning. 
While the American case study focussed its attention on a gifted black student, I did not find one New Zealand study that has considered the voices of gifted Māori students to inform discussion in this area, perhaps because the concept of Māori giftedness is still largely absent in academic literature. Bishop et al. (2009) focus their research on students whom each school in the study deemed as either engaged, or nonengaged, without further discussion of how these schools approached this measurement. Macfarlane (2004) has aligned his theoretical pedagogy of cultural centeredness with that of Bishop, but the focus of his research is that of students with learning and behavioural difficulties. Although these research studies that have made great contributions to our understanding of Māori education experience, a discussion of Māori students who experience success within English Medium mainstream environments are absent from both studies. The significance of what can be learned from Māori students who do perform well at school is arguably just as important as those Māori students who are disaffected from learning. I wanted to see what "Māori achieving success as Māori” means to them. Gaining this understanding required exploration of how high achieving Māori students navigate their schooling environment and what has contributed or hindered academic success.

\section{Māori homogeneity within Māori research}

Three research studies with a socio-economic focus were found through the keyword combinations of socio-economic, or SES and indigenous, or Māori and research. Marie, Fergusson and Bowden (2008), Boon (2008) and Nash (2001) from New Zealand and Australia, conduct qualitative-type studies to show relationships between these key concepts.

It was interesting to discover that all three SES studies are quantitative and relied on quantitative data to establish relationships that infer causality. Although each study appeared to define clearly how academic achievement is measured, the use of rigid categorical variables to describe participant identity limited each study in several ways. Marie et al. (2008) give their indigenous research participants a label of either Māori, or a Māori-other depending on how participants fit into pre-determined criteria. This binary measurement was designed to show that the higher rate of educational under-achievement amongst Māori was a consequence of disadvantaged SES rather than cultural identity. Australia contains probably the most diverse range of aboriginals in one country in all the world, however, participants of a North Queensland study are differentiated by an Indigenous, or non-Indigenous identity (Boon, 2008) when 
measuring at risk rates for dropping out of school. Nash (2001) measures Mãori students up against Pākehā to infer that it is prior ability, not ethnicity (through access to home resources) that accounts for the differences observed in school attainment (Nash, 2001, pp. 28-29).

Another relevant quantitative research study from Canada by Hallet, Want, Chandler, Koopman, Flores and Gehrke (2007) was found using the keyword combination of indigenous and achievement. This study parallels the research of Marie et al. (2008) because it also uses longitudinal data to explore the relationship between ethnic self-identification and drop-out rates. The study uses the term "aboriginal” to encompass a population of three distinct ethnic groups in Canada. Participants are asked to record whether they identified with being aboriginal or not, over a long period of time. Although the strength of these studies was in the sheer numbers of participants, there was no way of knowing how these rigid labels of identity affected the outcome. Two of the four studies (Hallet et al., 2007; Marie et al., 2008) acknowledge that they had adopted limited measurements of the ethnic construct and that this impact on their results was unknown.

An Auckland research study conducted by Fitzpatrick (2005) acknowledges the concept of "hybridity" and the impact that this has had on Māori students in schools. She states that the Ministry of Education needs to "recognise the voices of students, the complexity of students' lives and the environments and the problems with essentialist assumptions” (Fitzpatrick, 2005, slide 19). This argument is true of any current research that promotes Māori ethnicity as a measurable construct.

An issue each of these quantitative research studies raised was the impact that belonging to an ethnic culture had on educational experience. Each study sought to explain how ethnic/non-ethnic identities were to be measured and each study had a different way in which it was going to measure this construct within their research. I thought that the problem with any type of research that adopts cultural ethnicity as a variable is the assumption that Māori are a culturally homogenous group of people, whereas in fact Māori are every bit as diverse as Pākehā.

To date, there is not research from New Zealand that analyses educational differences between the working class and/or middle class cultures of Māori students. Current research has not moved past a dichotomous exploration of Māori educational experiences against those of Pākehā. Although I decided not to focus on middle class Māori, I believed that an investigation into multiple Māori identities could uncover 
social difference, thus demonstrating that Māori are not a culturally homogenous group of people. Poata-Smith (2008) states:

Māori are all too frequently discussed by culturally nationalists as if forming one homogenous entity, its members possessing exactly the same experiences of oppression, and exactly the same political aspirations. However, this ignores the fact that there exists a dynamic range of aspirations and political strategies within so-called "Māoridom". Moreover, these aspirations often conflict with one another and are not divorced from the influence of the wider social and economic environment. (p. 13)

I began to wonder what would be the implications would be for policymakers, researchers and practitioners if they began to look at Māori students as a socially diverse group. How could we incorporate this diversity into an educational experience that caters for the needs of all Māori?

\section{Māori girls and their multiple identities}

Two studies appeared to speak directly to Māori girls' achievement in schools. One study (1992) was conducted eighteen years ago. This research was quantitative and designed to analyse and measure Māori girls' achievement in a mainstream schooling environment (Carkeek, Irwin \& Davies, 1992). The other study was concerned with documenting the history of a school for Māori girls that was closed in 1969 (Matthews \& Jenkins, 1999).

In both studies, an exploration of the process of the research itself was as important as the findings. While acknowledging a feminist paradigm within their studies, both researchers felt it important to convey, as part of a Kaupapa Māori approach, the research steps. Clearly, further investigation of research studies is needed to build a more comprehensive picture of Māori girls’ schooling experiences.

These feminist studies emphasised the importance of taking into account the diverse contexts within which humans exist and the many identities they are forced to take in different situations. As argued earlier, current literature within New Zealand indicates an overemphasis on the Māori underachievement problem in schools. It has been argued that the focus on underachievement leads to essentialist assumptions about Māori students (Fitzpatrick, 2005).

Steele (2004) argues that social stereotypes related to particular ethnic groups can influence students’ self-perceptions, school engagement and identity development. 
Steele states that research studies conducted in the United States demonstrate that successful academic engagement in school requires students to develop positive schooling identities. This in turn encourages the student to feel they belong and are valued within their school. Forced identities (McIntosh, 2005) which are often negative stereotypes related to groups disrupt a sense of belonging and the development of personal identity as an achiever (Steele, 2004).

Research which acknowledges hybrid identities within ethnicity or research and has a specific focus on Māori success in education is currently scarce. Although Ka Hikitia acknowledges that Māori learners can be socially different: "Māori learners, a diverse group from a wide range of cultural and social backgrounds, all enjoying education success as Māori” (p. 9), the document speaks as though there is only one way of being Māori, or one Māori identity. Further examination of the schooling experiences of high achieving Māori girls would help to build our understanding of how hybrid or multiple identities affect academic achievement.

\section{Starting the Climb}

I was motivated by my initial analysis of this literature which guided me as I approached the foothills of the mountain. I felt buoyed by the knowledge that my research proposal seemed to vindicate the research focus, as I had found little analysis within the literature reviewed that would contribute to our understanding of diverse, multiple Māori student identities and their success academically and in school. However, I was uncertain of the paths I would follow upwards, and how the stages of the journey were going to progress.

I think I also knew that the significant challenges to identity that I had faced could somehow be overcome by listening to the voices of others and the stories they had to tell. I felt that there existed legitimate stories from the voices of contemporary Māori youth concerning their achievement in English Medium mainstream schools which had yet to be told in literature. Ultimately I hoped that this research story would prove to be a tale of celebration that acknowledged the many successes of the high achieving, Māori girls. After all, the current educational climate for the majority of Māori youth is still a hostile one. Many Māori students have the intention of setting off to reach the top of the mountain; not nearly enough complete the climb. 


\section{CHAPTER 2}

\section{Plotting a Path that is Transparent and Personal}

In this chapter, I describe the path that I intended to follow during the climb. I introduce the reader to the other participants of the study who undertook their own journeys over challenging terrain. I also discuss how my research process aligns with Kaupapa Māori methodology and can be considered under the headings of Representation, Legitimation, Benefit and Accountability and Initiation, as set out by Bishop and Glynn (2003, p.85). The process of Initiation was dealt with in Chapter 1 when I recounted my purpose and motivations for the study. But I am getting ahead of myself. Let me explain.

After viewing the foothills, I took stock of the tools with which I had equipped myself to ensure the journey would be successful. I decided that the research process would be guided by Kaupapa Māori methodologies (Bishop \& Glynn, 2003; Smith, 1999) and Personal Experience methodology (Clandinin \& Connelly, 1994). Kaupapa Māori processes provided explicit protocols which influenced the ways I interacted with the participants of this research. I found this particularly important as I conducted interviews and member checks. One particularly important protocol has been to keep the mana (self respect and dignity) of the participants in the forefront of planning and processes by ensuring that my path in the research process was made transparent to them. Travelling a transparent path is also an important aspect of Personal Experience methodology.

There are many similarities between Kaupapa Māori methodology and Personal Experience methodology that make the two work well in this research context. Smith (1999, pp. 217-218) identifies the following questions as important to Kaupapa Māori methodology:

- What research do we want to carry out?

- Who is that research for?

- What difference will it make?

- Who will carry out this research?

- How do we want the research to be done?

- How will we know it is a worthwhile piece of research?

- Who will own the research?

- Who will benefit? 
Bishop expanded further on these questions in order to challenge contemporary power relationships (Bishop \& Glynn, 2003, p.85). Central to this idea are questions that encourage the researcher to consider the personal biases that she brings to the research process. Similarly, Personal Experience methodology requires the acknowledgement of the centrality of the researchers' own experience; their own telling, livings, reliving and retellings (Clandinin \& Connelly, 1994, p.418) in the research process.

In Personal Experience methodology, the researcher is the storyteller who is “experiencing the experience" (p. 414) of others and relaying this in a storied form. Hence, the story which unfolds in this thesis uses my narrative voice. The treatment of time is also very important to this methodology. Questions must be raised about the storyteller's feelings (inward), the participants and their setting (outward), the participants' histories (backward), and where they are going (forward). Clandinin and Connelly (1994) write: “To experience an experience is to experience it simultaneously in these four ways and to ask questions pointing each way. . . experience is multifaceted” (p. 417). I will introduce the participants, position them as culturally located beings, consider who they are at the moment of their interview and set down my reactions to their schooling experiences. My feelings are sometimes framed by questions which are incorporated into the analysis of the interviews in chapter 3.

These methodologies work well alongside my theoretical framework. Schwandt (2000) states social constructionists: "take issue with what might be called meaning realism - the view that meanings are fixed entities that can be discovered and that exist independent of the interpreter” (p. 198). Personal Experience methodology has given me the tools to convey how I have constructed knowledge in relation to the participants of this study. By the end of this study, I came to see my developing understanding of postcolonial theory as an important instrument in this process too.

\section{The Issue of Representation}

Kaupapa Māori processes involved in conducting this research, from the time of its inception, to collecting and analysing the data, have all contributed to the story that has been told. This section will make visible those data collection and analysis processes that directly link to how participants are represented within this study.

Four high achieving, Māori girls whose schooling experiences and multiple identities are explored, consented to have their thoughts and beliefs as established through the interview questions discussed in this forum. Their views are sometimes reinforced and at other times, challenged, by a caregiver or a friend who they had 
selected to be interviewed. The four girls understood that sometimes they had no control over the personal opinions and perceptions expressed by their caregivers or friends about their schooling experiences. However, it was important to me that the primary participants felt they had some control over the research and interview process, so a strategy of power-sharing, based on Kaupapa Māori methodology, was implemented (Bishop, 1999). The girls were asked to choose the friend that they would like to be interviewed about themselves, so they felt that they had fair representation of themselves in this study. They were also asked to select a pseudonym that was personally significant by which they would be known in the thesis.

For the purposes of this study, I had given these young women a socially constructed identity by labelling them as "high achieving, Māori girls”. Although defining the girls this way is in opposition to ideas promoted within this inquiry, the label is needed to establish a common ground that these participants shared. From this starting point, I could explore multiple identities exhibited by the girls. I also found a scientific definition of identity to help guide my analysis from a study conducted by Stets and Burke (2000). They state that an identity is formed by the process of identification, or self-categorisation: "the self is reflexive in that it can take itself as an object and categorise, classify, or name itself in particular ways in relation to other social categories or classifications” (p. 224).

As I conducted semi-structured interviews with the participants and the themes of the study began emerging, the research focus narrowed so an emphasis was placed on those schooling experiences that intersected with Māori girls' multiple identities. Initially I had thought that I would focus on general schooling experiences but found that the data I had collected was overwhelming in size and scope. Once all the interviews had taken place I began to appraise the data critically and to consider how I would convey my perceptions and analysis of how the multiple identities that emerged affected high achieving, Māori girls' educational experiences (or vice versa). It was a vital part of the Kaupapa Māori research process that I member-check the conclusions I had drawn with all the participants of the study. This ensured that they were happy with my representation of their social reality (Clandinin \& Connelly, 1994, p. 423-424; Bishop, 1999, p. 204; Bishop \& Glynn, 2003, pp. 81-82) and helped the interview process evolve to one of collaborative storying (Bishop \& Glynn, 2003). The membercheck invited all participants to sign a transcript of the interview to confirm that what I 
had recorded was a true and valid account of what had transpired. ${ }^{5}$ I also met with the participants for a brief follow-up interview and to convey my findings (which had involved a shift in the research focus) and hear their thoughts about this information. During this time I encouraged the participants to communicate to me if they were unhappy, or wished to challenge any aspect of the research. Their responses to my findings were always positive, interested and encouraging.

McIntosh (2005) and other identity theorists I had read during the research process (Choudhry, 2010; Cole \& Luna, 2010) have argued that identities and identity formation is in a state of flux and determined by the social context of the individual. So it is important to acknowledge that the multiple identities of the high achieving, Māori girls, which surfaced from the data of this research, must be viewed only in context of when this research took place. Although a flux in identity can occur during the course a lifetime for individuals, young people especially are at a stage in their lives where they are working out who they are. In his interview, Karena described his daughter, Sophie's Māori identity, as latent and something he hoped "she'll really develop when she is older and has the time”. He suggested that she “didn’t necessarily have an awareness of this latent aspect of her Māori identity herself”. It appeared that his comments had come to fruition later on in the research process while Sophie and I member-checked her interview. She acknowledged that she had only recently begun identifying herself as New Zealand Māori on forms that asked for information regarding ethnicity, whereas prior to this she had ticked only New Zealand Pākehā, or both. She also said that if she was forced to choose one, it would be New Zealand Māori. Therefore, this study represents a snapshot of how these young women identify themselves at a particular stage of their lives during which they are moving towards full adulthood. This acknowledgement aligns with Personal Experience methodology which discusses the importance of locating participant experiences temporally. By doing this, the researcher is able to see that the participants' thoughts "are a sign of personal and social historical conditions that convey meaning in the present” (Clandinin \& Connelly, 1994, p. 417).

Personal Experience methodology also encourages the researcher to think about how participant voice is represented in the study and the way in which a researcher approaches the interpretation of experience within this methodological framework. The researchers' own experiences are central to the telling, reliving and retelling of participants' stories. I therefore realised that my voice would frame the voices of the participants (Candinin \& Connelly, 1994, p. 418). By relaying my Mihimihi and

\footnotetext{
${ }^{5}$ Refer to Appendix C
} 
personal background to this study in Chapter 1, and showing how they have affected decisions and influenced the outcomes of this study, I hoped to demonstrate transparency in the research process. Through doing this, I wanted to represent the voices of the participants in an honest and reliable light.

The questions and research structures posed by Smith (1999) and Bishop and Glynn (2003) have been central to this research so that Māori ways of knowing are promoted within this framework. This was personally significant to me because I was committed to celebrating the stories of Māori girls who had approached the mountain's summit in travelling their mainstream schooling paths.

\section{The Issue of Legitimation}

In addition to research processes that relate to the issue of representation are those that are tied to the legitimate authority of this text. In this section, I continue to make visible the decisions I have made within the research process, in order to show how my authority has shaped the story.

In the research proposal I foresaw that the four high achieving, Māori girls who would be the focus of the study would be from different schools in the Wellington region. I thought that different types of schools (a mixture of high and low deciles, public and private, or single-sex and co-educational) would uncover interesting data and themes to analyse.

Once tentative research questions were established I sought students within my co-educational secondary school work environment that fitted the participant criteria in order to test the suitability of the interview questions. The first two students who participated in these practice interviews so impressed me with their speaking eloquence that I became convinced that they had their own unique stories to tell. This helped me make the decision that my secondary school would be suitable for the research study.

My school's Māori roll is very small, so the number of potential candidates who fitted the criteria for this study was very limited. It was at this point that I realised the focus would be on girls because there were not enough academically high achieving boys to participate in the study. Once I had obtained permission from the students who were my first two interviewees, I sought and found two other participants for the study very quickly, as they were already very well known to me. I had taught them during their previous year of study and had some contact with them from my brief involvement with ManaTu (the school's initiative to support Māori students). Their caregivers and the friends whom they chose to be interviewed were also known to me, although not as 
intimately. I felt that my position as a teacher who is Māori in this school supported my entry as researcher in this context. These two advantages possibly enabled me to establish productive relationships with the participants more easily than if I had approached a school that was unknown to me.

Several experiences led me to believe that mutually respectful and honest relationships had been built between myself, as researcher, and the participants in this study. In all instances the semi-structured interview process took place kanohi te kanohi (face to face). I met with each of the high achieving, Māori girls and their friends at school, because it was pragmatic, and approached the interview process casually. I would introduce the interview questions but let the conversation wander if needed. I arranged to meet three of the four caregivers at their homes for the initial interview, but managed to visit them all at their houses at some stage of the research process. I was offered a hot drink here or there - macaroni cheese for tea by one mother - and usually sat for two hours discussing issues that went beyond the scope of the study. This proved to be the most enjoyable part of this entire research process. I was prepared to find out interesting information from each of the participants but it was the honesty and intimacy of their stories that surprised me the most. I could sense a real enthusiasm from all four high achieving Māori girls towards their involvement in the study. It was flattering to be identified as an exceptional Māori student and chosen to participate in a research study about your experiences, but what seemed to be more important was that they understood that there was a real need to address the underachievement problem that exists in education for Māori students. Involvement in this research offered them a small opportunity to contribute to this.

Once I had completed all my interviews with all the participants I came to realise that the new understandings I had gained from this process resulted from the participants retelling and reliving their experiences. I realised that my journey of learning was part of the research process, and that this needed to be signalled in the writing of this thesis. One way of doing this was to position myself as a traveller, alongside the 12 participants, on this research journey. This aligns with Personal Experience methodology, as Clandinin and Connelly (1994) state: "when we become characters in their stories, we change their stories” (p. 422). The importance of establishing transparency, by demonstrating on whose authority decisions are made concerning the interpretation of the results and the themes that emerged from the data, is doubly compounded by the personal connection I have to the school and the students in this study. 


\section{The Issue of Benefit}

As I have already noted, the research paper I had written in the Māori Education course had led me to believe that there was an existing danger of disguising the socioeconomic problems of Māori through identity politics (Boraman, 2005; Nash, 2001; Poata-Smith, 2008; Rata, 2004; Thrupp, 2007). I felt passionate about developing further research which could dispel preconceptions that promoted the Māori ethnic identity as a homogenous construct, as there seemed to be little attempt in contemporary research literature to acknowledge the points of difference within Māori ethnicity through other social, political and cultural contexts. I thought that research which incorporated aspects of diversity within Māoridom would help to do this.

A refined focus on Māori identities developed as I was conducting interviews with participants. I began to feel that there was a real need for further investigation into those multiple Māori identities that may have contributed to their high academic achievement. Additionally, participants described experiences and tensions stemming from issues of identity in an English Medium mainstream schooling environment. I felt that this investigation could be beneficial by demonstrating that Māori have diverse desires and aspirations that arise from the influence of other social identities. By highlighting the existence of diverse, multiple Māori identities I may enable further legitimate social change where it is needed in Māori society. Kaupapa Māori methodology aligns with this need to make a constructive impact on Māori society because it is "research that involves Māori people, as individuals or as communities, (which) should set out to make a positive difference for the researched” (Smith, 1999, p. 191).

My research paper also enabled me to think about how the scholarly literature that I had read evaluated Māori performance in mainstream education from a negative perspective. A focus on the educational experiences of Māori who are succeeding and how they are succeeding, could generate a relatively unexplored line of discussion for Māori in education. This was indicated to the participants at the beginning of the research process through the Research Participant Information sheets. ${ }^{6}$ During interviews, participants usually spoke of feeling enthusiastic about the research focus and how they were contributing to it. Sophie said: "I feel very privileged to be able to help with this, because it's very important”. Similar feelings were expressed by MJ: “I think what you're doing is cool. I think it's awesome." I also hope that the results of

\footnotetext{
${ }^{6}$ Refer to Appendix B
} 
this study prove beneficial on the path that this school is beginning to take towards a wholly inclusive Māori community.

\section{The Issue of Accountability}

Throughout the research process, I felt that I was first and foremost accountable to the participants and that I should tell their stories in an honest and reliable light. Memberchecking protocols have been integral to this process.

Ethical approval was sought and granted from Victoria University and these procedures, alongside practices within Kaupapa Māori methodology and Personal Experience methodology, encouraged transparency. In order to keep the ethical considerations of the participants at the forefront of this research, approval and consent from participants has always been of upmost importance. Participants were given Research Participant Information sheets that discussed all aspects of the process and the Research Participant Consent form ${ }^{7}$ highlighted that participants could withdraw at any stage. Verbal consent and compliancy was always forthcoming from the participants, however, I did struggle to get written consent from all participants before the interviews were conducted as some participants forgot to bring the Consent form along to the interview. Although two participants were happy to use their real names, I discussed the importance of anonymity for the school and other participants of the study.

The school also has a vested interest in the project. I have offered to deliver my findings from this study to the school's Board of Trustees and staff if they wish to take up the opportunity.

\section{The Travellers}

There were 12 other participants in this study. The first invitation went out to my primary research participants. These were four academically high achieving Māori girls whose multiple identities were the focus of this study. I then asked each girl to nominate a friend or peer who knew them well and so they also became the other travellers on this journey. As one friend was selected by each of the primary participants, I ended up with three girl friends and one boyfriend. Finally I invited each of the four primary research participants' caregivers to participate. The caregivers

\footnotetext{
${ }^{7}$ Refer to Appendix B
} 
comprised two mothers and two fathers. I have outlined the relationships between participants in a diagram. ${ }^{8}$

The following section provides a description of each participant as he or she appeared to me when I conducted the interview. It is important to note that I have used pseudonyms in order to protect their identities. Each participant was asked to nominate a name which had some significance to him or her. ${ }^{9}$ I have used these names and participants' own words in order to create a profile of each traveller. The name of each primary participant is in bold, followed by her caregiver, then the nominated friend. After the travellers are introduced, I summarise the characteristics of each group of participants and discuss the school environment, all of which have contributed to the educational experiences of the four high achieving, Māori girls.

\section{Sophie}

Sophie is a Year 13 student. She received an Excellence endorsement for her Level 1 NCEA results in Year 11 and a Merit endorsement for Level 2 NCEA in Year 12. Sophie is of Te Āti Awa descent. Her parents and grandparents hold Masters or Doctorate degrees. Sophie cannot speak Te Reo Māori, however she spoke fondly of attending her grandmother's tangi at their marae earlier that year and the esteem in which she was held by the Māori community. During our interview she appeared articulate, intelligent and self-aware. She acknowledged very early on that “I don’t look very Māori, so a lot of people are quite surprised to find out about that aspect of my heritage”. She has a fair complexion and dark hair. Sophie identified herself as New Zealand European/Pākehā and New Zealand Māori.

\section{Karena}

Karena is Sophie's Father. Like Sophie, he stated very early on in the interview "I don't look Māori’. He identified himself as New Zealand Māori and spoke about his immediate family's connectedness to their taha Māori. He deduced that from these experiences, Sophie was at “one end of the spectrum” in terms of her Māori identity. Karena said his Mother was not brought up Māori. During the late 1920s she was smacked at school for speaking Te Reo and her parents didn't support the development of the culture, so she came to it much later in life. As a result, "my sister and I were brought up with the background knowledge we were Māori and we were kind of slowly

\footnotetext{
${ }^{8}$ Refer to Appendix A

${ }^{9}$ Refer to Appendix C
} 
brought into that”. He thought that this had impacted on his ability to identify with his taha Māori side and confidence to operate in a Te Ao Māori world; issues that he acknowledged he is struggling with today. He admired his sister, who is really engaged with their iwi. He would like to have done what she has and invested time into really developing a Māori dimension. He stated that he can "stand up in a marae and kind of stutter my way through a mihi and a few phrases but after that, I'm at sea”. He hoped that Sophie will develop this too, when she has the time. He suggested that Sophie's Māori identity is "one of a number of ways she would see herself, rather than a primary way”.

\section{Richard}

Richard is a Year 13 student who is also Sophie's boyfriend. Like Sophie, he is 18 years old and also academically high achieving. Unlike Sophie, his academic passions are in the Sciences and Math subject areas. Richard said that he had known Sophie since Intermediate School. They met as Year 7 students who had been selected to be part of the future problem-solving elective class, a school gifted and talented initiative. Richard is Pākehā. Unlike most of Sophie's school friends, he was aware of Sophie's Māori ethnicity. He spoke highly of Sophie's family, especially her father. He had met her aunty and knew of her grandmother "who are quite strong, very smart, Māori women”.

\section{Marie Granger}

Marie is a Year 12 student who was new to the school at the beginning of that year. She had received a Merit endorsement for her Level 1 NCEA results in Year 11 and achieved Merit and Excellence grades in Te Reo Māori that same year. Marie is of Ngāi Tahu and Te Arawa descent through her father and of Danish descent through her mother. She can speak her Pepeha confidently. Her Danish ancestry is more physically prominent as her complexion is very fair and she has blonde hair. During our interview she appeared very articulate, bubbly and open about her schooling experiences. She spoke about her aunty as being "much more Māori” and of wider whānau gatherings and experiences where "our side of the family did feel quite out of place". Marie identified herself as New Zealand European/Pākehā, Māori and Danish and cautions "I am more than what you see. Don’t judge a book by its cover”. 


\section{Bill Bannister}

Bill is the father of Marie Granger and spoke proudly about his daughter. He introduced a connection to his taha Māori side at the beginning of the interview: "Our iwi is Ngāi Tahu with descendants from Kāti Mamoe and Waitaha, from the South Island... that's a connection that has been revived in recent times by my late mother who spent quite a few of her last years looking at the family tree and finding our whakapapa and tracing it back a long way, to Codfish Island, now Stewart Island. Our Pākehā ancestors came on the scene in 1817'. He admitted that his knowledge of Te Reo was limited: “I can’t give you a full Mihi but Marie could”. Later in the interview he spoke about his sister as being more fully immersed "in the Māori way of life". He paralleled Marie's appearance with that of his sisters, as she was as "blond-looking as Marie is, with blue eyes”. He spoke about Marie’s "being Māori” as “one of those blocks of her foundation ... she's got some Danish ancestry . . . we're a mixture of all the Scottish-English as well. She's aware and proud of it all”. During the interview we spoke at length about the challenges Marie had faced to her Māori identity because of her fair appearance.

Mary

Mary is a Year 12 student who had only known Marie since the beginning of the year, so she was initially unsure about how valuable her contributions to the interview would be. She admitted that she "didn't even know she was Māori, to be honest" when I asked for her involvement in the research project. She admitted she was wary about participating because her own knowledge of issues pertaining to Māori was limited. Mary stated that her Dad is a Kiwi and her Mum is American (from the United States of America). She describes herself as a "typical Kiwi kid with mixed culture".

\section{Lea Williams}

Lea is a Year 12 student who had been a participant of the school's initiative to support Māori students (ManaTu) since Year 9. She had received a Merit endorsement for her Level 1 NCEA results in Year 11 and achieved Merit and Excellence grades in Te Reo Māori that same year. Lea is of Nga Rauru me Nga Ruahine Taranaki descent. She can speak a detailed, traditional form of her Pepeha, one which her Koro had passed on to her. Lea described her ability in Mau Rakau and Kapa Haka as very good and she felt that she could confidently conduct herself on a marae. She began our interview a little 
reticently but later began speaking openly and honestly about her schooling experiences. She identified herself as Māori and identified strongly with her Māori heritage.

Jane

Jane is the mother of Lea Williams. She is employed as a Puna Reo teacher. Lea and her siblings were home-schooled by Jane for a significant part of their primary school education. Although Pākehā (and this is a term she states that she is very comfortable with) she is very staunch about kaupapa Māori and political issues pertaining to the tangata whenua of Aoteroa. She is also dedicated to ensuring that her children have an understanding of these issues too: "I have made a very conscious personal priority as a parent to my children, to take responsibility for actively supporting them in developing and appreciating their Māoritanga”. Jane provided visible, hands-on support to Māori students through ManaTu and the BOT, support that ranged from ensuring that there is an authentic Māori voice consulted within school-wide issues, to organizing a treeplanting at Matariki celebrations. Jane identified herself as tangata-tiriti and was direct about her Pepeha, her identity and how this translated within the context of Aotearoa:

I grew up in Wellington, born and bred, so I identify really strongly with this place, so I refer to Tarikaka as my Maunga. ... I I feel really solid in my identity with this place and that tangata-tiriti we have an obligation to . . . I'm really comfortable with the term Pākehā and I know that not everybody is but I prefer that to New Zealand European. We don’t have a really strong connection back to where our ancestors came from, so English, Irish and Scottish ancestry but those ties were kind of severed. . . . I didn't [use to] identify as Pākehā but how I identify as Pākehā and my Pākehā perspective would look hugely different to a range of other Pākehā New Zealanders because some would still be very connected to their Irish or Scottish background, you know, we might have been back to the "Motherland" you know, I've had none of that.

Pare

Pare is a Year 12 student who was Lea's selected friend for this study, however she is also a very close friend to MJ. Like Lea and MJ, she was part of ManaTu and had been since she arrived at the school as a Year 9 student. She considered herself Māori and acknowledged becoming frustrated by the lack of Māori culture around school: "When we go on our Nohos and stuff and then being around so many Māori things it's like 'Yeah, this is fun!' and then come back to school it's a real down buzz for us. We're like 'Man, I wish more Māori things happen here’”. Pare had aspirations to follow a 
career that had a Māori focus, something that involves the speaking of Te Reo and she thought Māori television might provide one such path. Pare was an age-group representative for the national Māori Hockey team and had encouraged Lea and MJ to take up the sport.

\section{MJ}

(initials of Michael Jordan, a basketball player from the United States of America)

MJ is a Year 12 student who had also been a participant of ManaTu since Year 9. She had received a Merit endorsement for her Level 1 NCEA results in Year 11 and achieved Merit grades in Te Reo Māori that same year. MJ is of Ngāti Porou descent and a proud descendant of Sir Apirana Ngata. Like her famous great uncle, she had firm beliefs about succeeding in both the Pākehā and Māori worlds. She can speak her Pepeha confidently and participated in Kapa Haka at school. During the interview I appreciated MJ's frank and candid manner in which she conveyed her views about her educational experiences. She is fair in complexion and identified strongly as Māori and with her Māori heritage. Of Māori students who choose not to participate in ManaTu she said: "They lose so much. Having the knowledge is important for me to pass on to my children”.

The Silver Surfer

The Silver Surfer is the mother of MJ. She had played in active role in MJ's education since primary school, with a particular focus on her sports. She had been MJ's basketball coach in the past and acknowledged that sport was an area that she received particular enjoyment from when she attended school. The Silver Surfer spoke about MJ's strong connection to her Māori identity and noted that at school MJ "loves her Māori”. The Silver Surfer identified herself as Māori but spoke about the importance of having the skills to function in a bicultural Aotearoa: "To us [The Silver Surfer and MJ's Father] you've got to survive in a white man's world, first and foremost, but also you have your tikanga and that, that's all well and good”. During the interview she reflected several times on how MJ's participation in ManaTu may have compromised her achievement in Economics; a subject that she perceives will be more beneficial to MJ when considering career prospects. 


\section{Hinemoa}

Hinemoa is a Year 12 student who was MJ's selected friend for this study. She also has a close friendship with Lea and Pare. She is of Ngāti Porou descent. She arrived at the school at the beginning of 2009, as a Year 11 student, and quickly became close friends with the other three girls through her involvement with ManaTu. Hinemoa was often the lead singer for school Kapa Haka. She commented: "I identify myself as Māori. I work hard in Māori things; try to achieve high - 'cos one of my strong points is Kapa Haka. I try to be a role model for the younger people who are doing Kapa Haka". Hinemoa spoke about the support she was able to offer MJ though ManaTu "She [MJ] is independent in her sports and everything but Kapa Haka is kind of, I dunno, she gets a bit shy - like everyone does - so you've just got to help her". This support is reciprocated by MJ with school work: "She would be like, 'C'mon, you can do it. If I'm going to do it, you can do it too' and I was like, 'But you're better than me' and then she'd be like, 'No, we can both do it, we're both the same'”.

\section{Characteristics of high achieving Māori girls}

All the participants were asked what characteristics had contributed to the high academic achievement of these Māori girls. Eleven of the twelve participants identified motivation and personal drive as contributing to their achievement.

She's quite competitive. She doesn't like losing. She sees it as if she thinks she can get Excellence in something and if she doesn't, she's just very disappointed with herself, so obviously that's a factor. The way she is with that sort of thing is she thinks she can do the best, she knows she can do the best. If she doesn't she's disappointed in herself, so she doesn't want that to happen. (Richard, friend of Sophie)

She's very determined that when she's got homework she just does it. She doesn't need too much urging at all. She's the first to volunteer, to come home and say she was going baby-sitting this afternoon, she had her homework with her, she would do it then. (Bill, Father of Marie)

Eight participants thought that the high achieving, Māori girls were independent learners and pro-active about how they learned. 
I think she has a funny way of learning actually 'cos she has to do things, like in P.E. for example, we'd be learning about bones and stuff and then she'll find the word similar to another word, like if something starts with a ' $S$ ' then she'll remember it as "small” and do actions to it for when we're doing an assessment, she'll do this action and it'll make her remember things like that. (Pare, friend of Lea)

I see her as being a good learner. I see her as being attentive and asking good questions to clarify things for herself. ... I get the feeling that she asks the right questions. She enjoys her learning a lot of the time. I think she has a commitment to her learning. (The Silver Surfer, Mother of MJ)

Seven participants said that being hard working contributed to achievement.

I think one of the consequences of who she is and how hard she works and who she sees herself to be is that she's done a lot of interesting stuff and pushed herself hard. Pushes herself probably too hard, actually. (Karena, Father of Sophie)

When we do work, sometimes me and my friends will be talking but she'll be working really hard. Sometimes she'll talk and then sometimes she'll just be working really hard. (Mary, friend of Marie)

Discussion from five participants demonstrated that having goals and future plans appeared to motivate academic achievement.

I want to be successful now to do what I want in the future. I really want to do event management. It motivates me because I want to be that. So I can’t just sit on my arse and do nothing. (MJ)

There's so many things that I want to do and I know the only way I can do any of them is if I do well in school. Like without the school qualification and all this knowledge and stuff I'm not going to be able to do all these things I want to in life. (Marie)

Other qualities that were raised by participants were reflective thinking, being smart and disciplined, and friendliness. Discussion from six participants demonstrated that each 
of the high achieving Māori girls felt that they had support from extended whānau and/or their whakapapa.

I feel a whole line of ancestors behind me who want me to do it. Kind of just helping me but apart from that, I want to make everybody proud, which I would definitely say is a Māori trait from me. I feel like I'm contributing to my whānau and community by educating myself. (Sophie)

Having discovered she had a whakapapa Marie felt proud about that. She felt really pleased about that. (Bill, Father of Marie)

I always go to the hockey games and if I can't then there'll be other family members. My mum's always there, likes to follow that and sometimes around my work commitments and my timing it's difficult to get there so Nanny will, or Dad will, or Aunty. So there's generally someone in the whānau there to support that. (Jane, Mother of Lea)

I think because she’s a descendant of Sir Apirana Ngata, it pushes her to do Māori a bit stronger because she holds that name. Most of the things that she talks about is about Sir Apirana Ngata. Like her English speech was about her Tipuna. (Hinemoa, friend of MJ)

\section{Characteristics of caregivers}

Nine of the twelve participants identified that a supportive and 'hands-on' approach to parenting aided the academic achievement of the Māori girls.

My parents are very supportive, very hands-on. Like whenever we tell them anything, like homework, they always have been helping us. (Marie)

They make out that they like me to be more hands off but I'm not a hands-off kinda person. I have been quite prepared to take quite a bit of responsibility for their education so I have to say I'm a hands on kind of person. I like to know what's going on and how I can support. (Jane, Mother of Lea)

Usually every day Mum asks how my day was and stuff like that. If I get a NotAchieved she's like "Oh my gosh, like we better sort this out now" (laughs). So that kind of pushes me to do better. (MJ) 
Three of the twelve participants thought that parents who were very encouraging, but not pushy, supported their academic achievement.

They don't push me to succeed because they know that I really want to succeed by myself but they're always there if I need a hand with anything. They don't ever say “Sophie, we want you to do well at school”. They don’t make a really big deal when I get a good mark or something, but I can tell they're happy that I do get good marks. (Sophie)

\section{Characteristics of friends}

Six of the twelve participants felt that the relationships the high achieving Māori girls had established with their friends were supportive in an educational context.

I'm there to support her when she needs it but usually I'm not so much there to offer a solution, just there to listen and then I usually do try to present a solution but it's not what I should be doing. I'm just there to listen and let her think things over. Just someone there to bounce things off. (Richard, friend of Sophie)

Three participants thought that these friendships helped in Māori contexts.

[I have helped her with] Kapa Haka, kind of getting her to sing by herself and trying to be independent. She is independent in her sports and everything but Kapa Haka is kind of, I dunno, she gets a bit shy, like everyone does, so you've just got to help her. Her first time singing a solo was with me and someone else. She did that quite well and now she currently can do it confidently. Not really confidently, but she can do it. (Hinemoa, friend of MJ)

However, five participants acknowledged a down side to having friends in class with them. Three of these participants were the high achieving, Māori girls themselves and they talked about how having friends in class could have a negative effect on academic achievement.

Like in Science last year, when I had to do Science because it was compulsory, I had two of my really good friends in my class, in my table group, we were all three of us really awful at Science, haven’t continued it this year and like, we still did all 
our work, but I'd say, if I didn't have them next to me I could've done better in the exams. I let myself get more distracted when I have my friends. (Marie)

I think it helps me to learn more [not having friends in the class]. Like I've learned heaps more in Bio that I did like year in Science because I had friends in Science last year so I didn't really listen at all. But this year, Bio, yeah I feel like I'm learning heaps more, just because I don’t have the distraction of friends in there. (Lea)

I get way more distracted. Yeah, I wouldn’t learn as much as I would. I probably wouldn't ask questions as much as I would. Just 'cos they're there and just 'cos I'm talking to them, I can't not talk to them 'cos you know and then I'd feel bad, sort of if I'm like "Shut up. I really need to learn”. I suppose I feel really bad . . . or if they're struggling, this sometimes happens in other classes, like English, if they're struggling I'll help them but then I miss out time doing my own work, sort of, so it's really hard. (MJ)

\section{The School Context}

These high achieving, Māori girls and their friends attended an English Medium mainstream, co-educational secondary school that has a Ministry of Education (MOE) socio-economic classification of Decile 10. Many of the school's processes gave it a liberal feel. For example, students did not have to wear a school uniform, school bells were only sounded at the end of interval and lunch and there is no end-of-year prize giving for academic, sporting or cultural achievements. Leadership was fostered through mentoring and mediation programmes, instead of the traditional, hierarchical prefect structure. In 2011 the Education Review Office (ERO) report stated that "inclusion is a strength of this college", thus reflecting the unofficial school motto: “Community, not conformity”. There were close to 1200 students who attended this secondary school; $59 \%$ are boys and $41 \%$ are girls. $85 \%$ of the student population identified as European/Pākehā and the next largest group ethnic group was Māori at 7\%. The school was in a transformative stage of setting up a system that will gather data about their Māori students and track their academic performance. This collection of data, initiated by the appointment of a new principal at the start of 2011 has suggested that the school is starting to explore the diverse Māori identities that exist within their cohort of Māori students. 
Four of the twelve participants of this study thought that the high achieving Māori girls felt comfortable and positive in all areas of the school environment.

She's made friends in every class she's been in. We've never had a bad report about behaviour from her teachers, so what does that suggest to me about her feeling comfortable? She's comfortable in those environments, whatever they are and she's been at a number of schools, so it's not like she hasn't seen variety, she's never complained about the classroom, or the class, the people that she's with or in. (Bill, Father of Marie)

An initiative designed to meet the cultural and social needs of Māori students had been running in the school for several years. It had succeeded in raising the profile of Māori culture in the school but at the time the interviews took place, was still developing continuity because of staff changes. I approached Jane for a suggested pseudonym for this study and she volunteered ManaTu, which I have adopted. Lea, MJ, Pare and Hinemoa were considered by staff, students and the wider school community to be important Tuakana (role models) for the younger cohort of Māori students that attend the school.

Six of the twelve participants spoke about the supportive role that ManaTu had on the educational experiences of MJ and Lea. Five of these participants relayed favourable comments that acknowledged the kind of support ManaTu offered. Support ranged from academic to pastoral needs of the students.

I just think the whole ManaTu concept allows you to shine in whatever capacity and gives Lea that strong identity and that strong, secure base of whakawhanaungatanga (the process of getting to know others) that allows all the rest of it to grow out of that... For me and my perception it’s largely about ManaTu which is about solid relationships which support that identity. . . . I'd have to say the tikanga Māori for me, you know those values, those really strong values of Manaakitanga, looking out for each other, and Tuakana/Teina and again the role models, the mentors, the kaiako setting high benchmarks and giving them opportunities to view things in a Te Ao Māori and do it within a Māori framework and allows them to solidify, be confident in who they are and where they fit and out of that, have the strength and the determination to pursue their goals and know that they're going to get the support they need to do that in. (Jane, Mother of Lea) 
All of the participants in the research acknowledged the positive impact that teachers within this school context had made in the academic lives of the high achieving, Māori girls. In general, the responses from all 12 participants of this study described schooling experiences that were positive and encouraging of successful academic outcomes for the high achieving, Māori girls.

\section{The Research Questions}

The journey was underway. I had my interview questions ${ }^{10}$ to guide me, so I proceeded to travel with the participants up paths formed by the stories they told, that described the mainstream schooling experiences of the four high achieving, Māori girls. I began the journey with the three interrelated research questions that I had developed for my research proposal. The main research question was:

How and in what ways do high achieving, academically successful female Māori students succeed in an English Medium mainstream schooling environment, and how do participants perceive schooling experiences that encourage/discourage their academic success?

Sub-questions included:

What are the multiple identities associated with high achieving, Māori girls and that are particularly related to their academic success?

What are some of the tensions associated with the multiple identities of high achieving Māori girls within an English Medium mainstream schooling environment?

However, it was not long into the journey when I began to lose sight of a path and a sense of direction. The research questions were generating an abundance of data, too much to deal with in a three paper thesis, and I could feel myself being pulled in different directions. Towards the end of the interview stage of the journey the subquestions were modified and became the main focus of this inquiry.

${ }^{10}$ Refer to Appendix D 


\section{CHAPTER 3}

\section{Navigating Precarious Paths}

In this chapter, I present my findings to the research questions by relaying and retelling the experiences of the participants. I present their stories under headings that represent the identities and tensions that were revealed to me over time. This account is shaped by my perspective, as Clandinin \& Connelly (1994) state: "When converting Field Text to Research Text the search for patterns, narrative threads, tensions and themes are created by the writer's experiences” (p. 423). A struggle that I faced when organising these Māori girls' multiple identities into a coherent pattern was managing the complexity of the data. Initially I could not see the interrelationship between identities and tensions. The multiple identities I uncovered were either visible to the girls, or lay beneath their consciousness because they were imposed by pressures of society. I believe invisible identities, which have been unacknowledged in scholarly literature, created tensions for the high achieving, Māori girls in their school environment. Working through this process made it difficult for me to analyse how my research questions were being addressed, so it felt as though I was travelling a precarious path. I came to the realisation that it was too difficult to separate identities from tensions, so the story that emerged from the data reflected the fluidity of these two concepts and how they both work together to answer the research questions. I also found that many aspects of the data appeared to contradict each other. By the end of the research process I realised that identity is a far more complex construct than I had first thought.

A foundational reading passed to me during my literature review has been crucial in my development of this analysis. McIntosh (2005) discusses Māori identity as being Fixed or Traditional (pp. 43-46), Fluid (pp. 46-47) and Forced (pp. 48-49). Although I drew heavily on her conceptual understanding of these identities, it has become a framework which has helped me tell the stories of these research participants and their unique experiences. By the end of the research process I came to realise that it is the ways in which these girls navigate these multi-faceted sides of themselves that give us some understanding of how they succeed as high achieving, female Māori students in a mainstream schooling environment. 


\section{Fixed or Traditional Māori Identities: The Established Route.}

In her paper, McIntosh introduces a Fixed or Traditional identity as being "a contemporary identity that is articulated by Māori [that] can be characterised as presenting particular identity hooks as markers of identity” (McIntosh, 2005, p.43). "Markers of identity" are fixed because "it comes with a set of expectations that someone will not only 'be' Māori, as indicated by knowledge of one's whakapapa lines, but will also 'know' what being Māori is and will 'act' Māori’' (McIntosh, 2005, p.44). Two of the primary participants, MJ and Lea, appeared to embody the values of this traditional identity. In the schooling context they participated in things Māori; Kapa Haka, Te Reo Māori, involvement with ManaTu and they were supportive Tuakana role models for other Māori students. The interviews with these girls, and their associated participants of the study, demonstrated that they had strong views on what knowing, acting and being Māori involved.

I have had two teaching experiences in bi-lingual units in schools where Māori students have out-numbered their non-Māori peers. This has shown me that drawing on whakapapa, mātauranga Māori, Te Reo and tikanga can make learning relevant to Māori students by legitimising a Māori voice in a schooling context where being Māori is the norm. Within the school that this study was conducted, the traditional Māori identity was a marginalised identity as the majority of students belonged to the dominant Pākehā culture. This study helped me see that the support of an initiative, such as ManaTu, could empower and validate students and foster traditional Māori identities; however as the interview process progressed I began to see that there appeared to be a tension between this identity and striving toward high academic achievement in this English Medium schooling context.

\section{Affirmation of traditional Māori identity markers at school}

For MJ and Lea, acknowledgement of a traditional Māori identity in other curriculum areas seemed to have an impact on their feelings towards and achievement in that subject area. Lea acknowledged the work of an English teacher who she felt was making a real effort to incorporate Māori into her curriculum and make the Māori students of her class feel welcome:

She’s [English teacher] really cool. ... She got us [Lea, MJ, Hinemoa and Pare] all in the same English class. We're covering more Māori stories and then the class might be doing different stuff, if we choose to do that. 
Q: Do you reckon that's working for you?

I reckon it’s good. Like even though I quite like having group discussions, you know, like when the whole class does that and 'cos we do that [different Māori text] you can't really but we just talk with ourselves and with Miss comes and helps us and yeah I like that.

MJ's Mother, The Silver Surfer, also acknowledged the efforts of this teacher and suggested that this has had a positive effect on her daughter's academic achievement in English.

She got an Excellence on one of her recent papers. ... She'd actually written it in Māori and she had to translate it back into English . . . . The teacher was able to give a topic that was more meaningful. Whether she had to choose it, or had to come out of this group of topics, I really don't know but that has aided her achievement. . . . I'm glad to see some of the subjects have changed in terms of what they offer our kids and I think that in itself aids achievement.

Both these accounts suggest that for those students who are seen to have a traditional Māori identity at school, efforts to accommodate and show acknowledgement of their Māoritanga in curriculum have positive academic outcomes, and enhance their willingness to engage with the curriculum.

Participants who were connected to MJ and Lea also commented on the positive support that was provided through ManaTu. The establishment of this initiative occurred when MJ and Lea had just entered college and they had watched the support group grow and develop during their time at the school. Lea acknowledged this support in her interview: "The ManaTu class, like that's probably the main supporting line and just how the principal and other teachers help support [it which] helps support us”.

Jane was able to compare Lea's schooling experience with that of her eldest daughter. ManaTu had not been established at that time she attended college. Jane believed that this may have been detrimental to Lea's sister's academic success:

My personal view is that if she'd had something like ManaTu right from the start that the way things panned out for her might have looked quite different. I do really recognise that for Lea that I see that as being . . . why she's having a really good journey and I feel really confident in the way she’s being supported. Being a single parent, working mother who it's quite hard, you know, the kids have to be 
quite independent. So knowing that she's within a secure environment of that whakawhanaungatanga is huge for me and I had a lot more concerns and worries for my older girl because we didn’t have that.

The Silver Surfer also spoke about how ManaTu had supported MJ's sense of her Māori identity within school:

I think at this school what's really helped MJ is having the Māori network, because she considers herself Māori, that's it. Which is great. It's been good for her because she just relates to that. She relates to the people, that whole thing and I think that's help keep her - I suppose in some ways - help keep her interested at this school. A reason for going to school, because there's been times when she wasn't really wanting to go, not because of the work, but just the environment at this school. So I think the Māori group has been very important for her in terms of her growth and making her feel like she has a place, has friends there. 'Cos she identifies with them more so than anyone else at the school.

Jane also discussed the importance of having a space that was identifiable as belonging to Māori students.

I think it's cool that they've got a space as their own that they can identify with . . . there's a kitchen that you can manaaki Manuhiri and that they can prepare their own kai and have a bit of independence. I'm sure that they would perceive that room as different to other classrooms and to me, part of that is the cultural context. They do karakia and they do waiata and they don't just sit and do bookwork and it's not purely around the academics. . . . The identity that this is our space, it's comfortable, it's got a good vibe, it's multi-functioning. I think it's really important to honour ManaTu as ManaTu in terms of meeting the needs of Māori children.

Hinemoa had observed MJ studying in this space. This suggested that this environment that had been created for Māori students was "multi-functioning". It could accommodate and was supportive of tikanga Māori but it also provided MJ with a space to pursue her academic needs: 
[I see MJ studying] in the Māori room, or just at lunch time and interval. She might have a test coming up, so she'll just get out her books and start studying. Or if she was unsure of something she'll just do it.

Hinemoa also acknowledged that it is place where Māori students can just be themselves: "I think the Māori room [is the place where MJ feels most herself]. That's where she hangs out the most. We can just do whatever. There's no right or wrong, kind of thing.” Pare, Lea’s friend, expressed the same belief about the support provided from having a Māori space. She through that it enabled Lea to "express herself and do all her little wacky things she does in class . . . whereas in other classes she just holds back a bit”. These thoughts were validated by Lea's response to the same question in her interview:

Definitely Māori and ManaTu [are the classes that I feel most comfortable in]. Those two, but one of the ones out here, um, probably English because I've got my three good friends in it, it's MJ, Hinemoa and Pare.

These comments indicate that care was taken by staff and the school to support these Māori students as "culturally located beings" (Bishop, 1999; Bishop \& Glynn, 2003; Bishop \& Berryman, 2006; Bishop et al., 2009), which did help to keep them engaged in school. However, a comment MJ made suggested that she didn't see the academic value of the ManaTu as a school subject. Although it was not negative, it indicated to me that perhaps she saw the value of the subject differently to how others perceived it.

I suppose, like, taking the subject ManaTu doesn't change, like, how I approach things in any way. It's just something else for me to do. I don't think that that helps me to be better; it's just a fill in thing.

While her mother, The Silver Surfer, acknowledged the benefits that ManaTu had brought MJ in terms of her traditional Māori identity, she had concerns about how it was meeting MJ's academic needs. I came to see this as a strong tension within this identity, as I saw participants had different beliefs about what constituted "Māori achieving education success as Māori” (Ka Hikitia, 2009):

When she came in [to the school] she had to drop some options to do Te Reo . . . So that limited what she could take in Year 9, Year 10 and when you took ManaTu 
you were expected to take Māori and that was one of our concerns was that she probably would've done Economics then. I suppose that in itself, perhaps, has limited her academic achievement because she's had to make a choice on something that perhaps she would've done differently. You've just gotta have your qualifications behind you if you want to do something and I didn't want her narrowing her choices too much.

\section{The importance of "knowing" and "acting" Māori}

MJ discussed in depth her perceptions of what it means to be Māori. It was important to her that she be perceived as Māori by others in any social context:

I haven't given up anything [of her Māori identity]. I'm still just as Māori as when I started and I still do the same Māori things as when I started. Um, yeah, I don’t change, I don't like to even if you had to I don't really. Like even if you had to change I couldn't, ‘cos then I'd get like down on myself for it.

She tried to articulate the difference between being Māori and Pākehā. For her, there are defining characteristics between the two and different ways of acting and behaving in school and in society. These thought arose after I asked her to think about the difference between her Māori class and the mainstream school environment:

There is a difference because we're closer and because you can, I don't know, you could say things to each other that you couldn't say to someone else in another class. You know like, "Sup", or "What a bloody Māori” You know [laughs] but if you said that, like if me and Lea said that to each other in Maths, everyone would be like, “oohh” you know, like they can’t say that, like the word Nigger, like black people can say it but white people can’t. . . . [In] English and Math especially, it’s the Māori kids that have a really good relationship with the teachers. Like we walk in "Hey Miss", you know we're the only ones that say hi, you know we just walk in happy, like normal and like the others don't do that and that's like weird to me. I just walk in and I'm like "Hey Miss” you know, “How was your weekend?” whatever, you know and we have that kind of, like we're friends . . . it's just the way that Māoris relate to other people. . . It just feels like it’s so much easier to meet another Māori person than to meet another Pākehā person 'cos their like, you know, they're different ... the way they relate to people. 
While MJ spoke about the support she found through her friends and other Māori people, Lea spoke about how maintaining a strong Māori identity and sense of self helped her in a schooling context where the Māori population is marginalised:

I'm not saying it's hard to exist here but I think it sort of would be easier for them [high achieving, Pākehā girls], than if you were Māori because . . . if I didn’t really know my identity and [if I wasn't] strong in my Māori side . . . and I was at this school, I'd find it hard and probably lose that.

Q: Like lose your identity, or lose your will to - or lose the opportunity to succeed? Not lose the opportunity to succeed. I'm talking more about losing my Māoritanga because I'd be, like, shy of my Māori side so I wouldn't be proud to be Māori. But for [Pākehā], I think they'd find it easier to fit in and, I don't know if they'd do better academically, maybe, but yeah, I'm not too sure.

Q: So are you saying, you know keep correcting me if I'm wrong, but because you have a strong sense of self and who you are, then that makes your path through the system easier?

Yeah.

Q: Whereas if you didn't have that sense of self then you wouldn't be able to achieve as strongly?

I think, or not achieve as strongly but feel more comfortable outside in the school, you know, it would affect how I'd work.

Both Lea and MJ indicated disapproval of Māori students who choose not to maintain a traditional identity all the time. MJ found it difficult to understand why other Māori students would choose to relay their identity differently:

I think some of them [students in Māori class], like they recognise they're Māori when they're in Māori, but out, when I see them in town hanging with their . . . they all have Pākehā friends. Like it's really me, Pare, Lea and Hinemoa all together, and we're Māori where ever we go, whatever we do you know, anywhere but then you see of like the likes of Sonny [pseudonym], he hangs out with you know, all those people, you know all the Pākehā or Asians, or whatever, you know, he's not . . . if we see him, he's not Māori. Like to me he doesn't, he's not the same person as when he's around Māori people. They change, they're not as friendly, they're sort of standoffish, kind of. So, that bothers me 'cos it's kind of like, ‘cos I couldn’t do that. So I don’t know how they do that. 
Lea also shared similar views about students who do not openly appear to identify as Māori at school. When she was asked what she thought about Māori students who choose not to participate in Māori activities at school, she didn’t think Māori students were really “into it [being Māori]. I don’t think they want to acknowledge that side of themselves".

\section{3. “Being" Māori - an ability to whakapapa}

MJ felt that she would find it easier to relate to Māori teachers at school. They would understand her better because they shared an understanding through being Māori:

Ideal teacher? Someone who, for me it would be someone who's Māori, but, you know, cares about both sides, both Pākehā and Māori, really Māori-ness, you know Māorified.

Q: Is it important for you that they ethnically identify as Māori?

Yes because . . . if I was feeling eeer [sic] about something, like not even to do with school, they would sort of understand how I feel, so it's sort of easier for me to open up, I suppose. Yeah, so I can’t talk to someone like German about... [laughs] 'Cos then they'll be like “I don't know what you're talking about” [laughs]. Just the vibe as well, of being a Māori, I suppose. (MJ)

Jane also thought that Lea would have more affinity with a teacher who was Māori and identified strongly with their Māoritanga:

I don’t know if she'd identify it but I obviously think that if she's got somebody that's Māori, who's strong in their taha Māori, I would identify that as a bonus and a strength. So potentially she would identify someone who is strong in their identity and maybe has more than one cultural background to draw on.

Lea's friend, Pare, spoke about what it like to be in class with Māori friends: "we can distract each other but then in a way it's cool to have Māori people around you because you know you're not alone”. I understood the rationale of grouping Māori students together and how this could support students whose culture was marginalised. However, I had my own concerns about how it could be affecting academic achievement. I had been involved in the bilingual units of the previous two schools I had taught at. In both institutions I felt frustrated at what I thought were low academic expectations placed on Māori students. I thought that a focus on building a traditional 
Māori identity at the expense of academic achievement was patronising and not helping students to progress. MJ gave a frank account of what it was like to learn in a classroom of Māori peers who were de-motivated learners:

In our Māori class there's a lot of kids who don’t want to learn, just don’t care, you know? So it's hard to like motivate yourself sometimes when other people around you don't want to.

Q: Are you talking about all the classes?

No, especially in Māori. Like with other Māori students. You don't see many other Māori students trying their hardest and wanting to learn or wanting to do something, they're pretty laid back, so it’s harder. I find it harder.

The interviews with MJ, Lea, their friends and family conveyed the importance of having the traditional Māori identity acknowledged and nurtured within the mainstream schooling environment. Participants were able to articulate clearly their views of how this could be achieved. I learned to view the traditional identity as the culturally homogenous identity which I have previously referred to in literature pertaining to Māori Education. The research of Bishop (1999), Bishop and Glynn (2003), Bishop and Berryman (2006), Bishop et al., (2009) and MacFarlane (2004) had ensured that those students who expressed traditional Māori identities had been given a voice.

It seemed to me that while these stories reflected an established route up the mountain, there were contradictions in this data which signalled the dangers of promoting a traditional, homogenised Māori identity in relation to high academic achievement. This led me to question what "Māori achieving success as Māori” meant in this schooling context, as ideas about this appeared to differ amongst participants. While I still felt firmly grounded to the research path, visibility was poor. Despite this, I continued to forge ahead.

\section{Forced Identities: The Unmapped Trail}

Further analysis of the interviews with all the participants revealed data that aligned what McIntosh (2005) calls a Forced identity: "The forced identity is one that is predominantly based on the perceptions of the outsider group” (McIntosh, 2005, p.48). In McIntosh's article, this identity is discussed in relation to negative stereotypes perpetuated about Māori which stem from the disadvantaged position Māori hold in many aspects of society. Lea, MJ, Hinemoa and Pare all spoke proudly about being 
Māori and conveying their Māori heritage at school. For all of them, expressing a traditional Māori identity was linked to expressing a significant part of who they are and how they located themselves as cultural beings. However, they also presented negative experiences that stemmed from the stereotyped attitudes of some Pākehā peers at their school. On one level, these four Māori girls would have been known to their Pākehā peers as the individuals that they are, but on another level their stories demonstrated that they were attributed with negative characteristics because of their ethnicity. This study also found that another type of forced identity seemed to be cast upon Marie and Sophie. Although they might not acknowledge that they were forced into being Pākehā at school, I felt that their schooling experiences demonstrated that the attitudes and assumptions of others made claiming a Māori identity within this context a very difficult choice.

\section{Coping with stereotypes}

In their interviews, Lea, MJ, Hinemoa and Pare told narratives that exposed stereotyped attitudes and assumptions members of the Pākehā school community have towards students who openly claim a Māori identity. Their feedback also conveyed their acute awareness of how being Māori influences the attitudes and beliefs of others. MJ felt that her Pākehā peers had certain expectations of her, as a Māori student:

Some people they think Māori they're like “Oh, be scared of them” kind of thing. You know, I'm not scary! Well I don't think I'm scary but they're like, you know. I think that some people, because they know you're Māori, they know not to get in a fight with you, not to piss you off.

Q: Is that a sense that you get in classes or around the school?

Both. In class, out of class. You just notice that and even when I'm on the bus going home if there's an argument they'd be like, “Ooooh, MJ, go beat her up for me” you know. That's why I think because you're Māori, you know you're meant to be tough.

Q: Where did that come from though? Is it the media?

I think it is. "Never shake your baby" is Māori [laughs]. [It appears that] All people that kill people are Māoris, but actually there's Pākehās that kill people too.

Hinemoa discussed her beliefs related to how Pākehā peers perceived Māori students at school. She recognised that they saw her as "different, like 'neat' or something” but she 
also identified an undercurrent of fear: "We have days where people from around the school can come into the Māori room 'cos sometimes they're a bit scared”.

I talked to Lea about the effects of stereotyping Māori students during our member-checking interview. She thought that negative stereotypes came from other students - not from teachers. Lea also thought that Māori students who were disaffected from learning at school had bought in to these stereotypes by thinking "If that's what they think of me - that's what I'm going to be”. However, she had found the motivation not to follow this path:

People seem to think that Māori don't achieve at school, especially highly. The stereotype is that it's not not normal to achieve - it's not normal to want to achieve. I just don’t want to be perceived like that - as not achieving.

MJ believed that negative stereotypes about Māori are circulated and reinforced through comments made in class by her Māori peers:

I've heard people blame that they failed a test just 'cos they're Māori, you know? It's sad because I don't think that and I think that hurts me. I feel hurt, sort of, because they're putting a negative name on Māoris. You have all these people out there trying, you know like Māori people, trying to do good and then there's just this dude that's like "I failed just because I'm Māori - all Māoris fail", just because they failed. It's not fair and it hurts other people. I mean you don't really hear someone go "I failed because I'm Pākehā", so I don't like it. I just think they need to sort their shit out [laughs].

However, she did make a comment towards the end of her interview which suggested that even though she acknowledges negative stereotypes exist, she looked to her Māori identity as a source of inspiration for achievement: “There's some stuff you can say because you're Māori that's what you did, because you're Māori, you know? Like everything I achieve, I do because I'm Māori.”

\section{Institutional racism and deficit theorising}

Significant challenges to Māori students and their identities at school are the inherent biases towards the mainstream, Pākehā majority that are perpetuated by the structures and processes put in place by English Medium schooling institutions. 
Many participants felt that it would be easier to achieve academically in a mainstream school environment if you were Pākehā because this was the dominant discourse reflected to them at school. Pare and Lea spoke about the issues faced by Māori students because their culture is marginalised. Marie felt that Pākehā teachers probably related to Pākehā students better and that this would favour their achievement. Pare also expressed discontent that Māori should have to adapt to suit the mainstream context. Early in the interview she spoke about how Pākehā students “wouldn’t have to worry about their culture and . . . act like someone they're not”. Her thoughts acknowledged the barriers created by institutional racism for those Māori who choose to assert a traditional identity at school:

I reckon we don’t - as Māori people - I don't reckon we express ourselves as we should. We kind of go into a little hole, when we go out into the school and stuff, this is weird being around a lot of Pākehās, but then when we're in the Māori room and everyone's together it's like, “Oh yeah, this is cool, this is what we think school's supposed to be like".

Q: So how does going out to the mainstream school change you guys?

I think it's because we have to try and make ourselves fit in with everyone else. Like really we don't want to but we have too to make us fit in.

Pare felt as though she and her Māori peers were forced into conforming to Pākehā cultural expectations when entering mainstream areas of school. It appeared to me that although efforts could be made to support these students as culturally located beings within some culturally supportive environments, the expectation was not maintained in all areas of the school.

Lea recounted the comments expressed by Pākehā students because of her involvement with ManaTu. Her Pākehā peers would challenge her about engaging in ManaTu activities that interfered with her normal timetable, by saying that they were getting "special treatment”. Lea was able to rationalise their arguments, by saying: "It's not really special treatment it’s just more support, I guess, because we're different.”

Jane spoke at length about some of the institutional challenges ManaTu faced to maintain its survival. She spoke about fighting to get more Māori knowledge into the school curriculum. At one point she had to encourage her daughter to weigh up the value of Māori knowledge against Pākehā knowledge. This indicated to me that 
different views existed about what "Māori achieving success as Māori” (Ka Hikitia, 2009) meant amongst participants:

It was part of the growth of ManaTu, part of the evolving was actually getting it within the curriculum school context. That has meant the school really rethink things. .. . The way it was actually trying to fit ManaTu within the school context was actually compromising our kids choices and opportunities . . . it was not encouraging more people to participate, people were considering opting out to try capture other [subject] options.

Q: Was that because you had to take Māori and ManaTu [together]?

That was a real issue because that was creating some inequities. It wasn't going to capacity because people were going to drop off. I had a bit of a [battle] with Lea. I could understand what she was saying, but as a parent I was saying, well, actually you're not not going to do ManaTu. . . . Ok you might not have some of these [academic] options but that within the ManaTu context you've still got to see that there will be many, varied holistic opportunities that within a kaupapa Māori context that will equate with, or be the flip side of the losses of other things. Again it's about that not perceiving the whole thing as "I get less this way and I get more that way" it's about how you look at it really, in terms of what you value about what can come out of [it].

\section{3. “Being” Māori, “looking” Pākehā}

A particularly interesting finding in this study was whether or not primary participants made a conscious choice to assert a Māori identity within school. As I re-read and evaluated Sophie and Marie's interviews, I found myself intrigued by the idea of whether or not there was always choice involved in making this assertion. Although each of the high achieving, Māori girls had laid a claim to their Māori heritage by having this information recorded on the school roll, Marie and Sophie chose to engage in school activities on a level that paralleled their Pākehā counterparts. Their fair complexions and ability to engage comfortably, and succeed, within a mainstream schooling environment allowed them to be perceived as the Pākehā norm. McIntosh states: "Many Māori live lives that are at the margins of both mainstream as well as Māori society” (McIntosh, 2005, p. 48). It was this statement that led me to consider the challenges and tensions experienced by Marie and Sophie in asserting a traditional Māori identity. Their non-Māori appearance, and the stereotyped attitudes of others 
which arose from this, excluded them from fitting easily within Māori initiatives at school.

During her interview, Sophie acknowledged that her experiences of school aligned with the Pākehā norm because this was how she was perceived by others: "I think because I'm perceived as Pākehā most of the time . . . I don't know if I've had it easier or harder than people who actually look Māori. Karena, Sophie’s father, also felt it was difficult to make judgements about Sophie's experiences at school as a Māori student because of her appearance. He also thought that looking Māori within his educational context had its advantages:

It's a little bit difficult and being specific about Sophie, it's a little bit difficult because she hasn't necessarily got that visible Māori culture to bring along. I actually would think in many school environments - and this is partly from being a teacher and an academic in a university - actually I'd say it's kind of almost the other way around. I'd say that the Māori students who choose to express their Māoriness, who choose to express that creatively, they get a wonderful reception. They get a really good reception because it's valued and actually that would be my experience. It's actually, in some ways, it's the other way around.

During the interview Sophie was able to reflect upon how her fair appearance may have influenced the friends she had made at school. This led her to discuss the implications of how participating in school-led Māori initiatives could isolate her from the safety of this established friendship group:

Because I don’t look Māori all my friends are Pākehā. I don't have any friends with the same Māori heritage as me. I don't think I have any Māori friends. Apart from Nina. She's lovely. So that was another thing about joining in with the [Māori] school stuff and separating from my peer group that I've been hanging out with since I've been this tall [gestures a height that suggests Primary School] and into another one, which would be a bit strange.

Sophie also felt that her appearance would intrude on her ability to be Māori in contexts outside of her family:

In Year 10 I had Mr. Hart [pseudonym] who was a lovely guy. He really did try to get me to do that sort of stuff [Māori activities]. Especially because I don’t look 
Māori I don't think it's that easy. I don't think I fit in well except in the family side of it, where everybody understands and everybody knows.

The reactions of others to her claim of a Māori identity also influenced Marie's decision to keep her identity hidden within a mainstream schooling environment. Some schooling experiences and discussions with friends and peers about her Māori heritage had cumulatively reinforced the message that she couldn't be Māori because she did not fit their idea of what a Māori student should look like.

Her claim to a Māori identity was challenged during her initial participation in Te Reo Māori at her previous secondary school. Others members of her school community, particularly her teachers, made assumptions about her identity based on her appearance:

In Year 9 we were doing our Mihis and I volunteered to do mine first because I love debating and public speaking. I did mine and no-one else wanted to go after me and the teacher's like “Look, Marie went first and she's not even Māori” and I was like, “Actually, I am!”

Her father, Bill, recalled this moment in his interview also:

Up until she stopped learning Te Reo she had great experiences as I recall and only once was ever a sad one, or a bitter one, but she overcame that. It was the old "Why are you a Pākehā, not a Māori” and so she was able to, by being able to recite her Mihi, her critics shut up quite quickly. So she had a quality, good time after that.

Q: Can you tell me about that experience?

In Year 9, as one of probably the only blonde Pākehā in the class, so there was some challenges to her - to her identity. So she was able to Mihi out. It was something she felt very happy and strongly about so she learned. She learned Te Reo at that level and went on to do it again at the next level and was highly acclaimed, so she had a great time.

Marie and her father felt that negative attitudes and stereotypes, primarily based on her fair appearance, had influenced her decision not to continue studying Te Reo Māori when she joined this school at the beginning of the 2010 year. Although she had loved 
Te Reo Māori at her prior school, something changed when she joined the Māori class at this school:

I was going to do Māori this year and I went there on the first day and I really felt unbelievably out of place. I felt sick. I felt so uncomfortable there and so I changed out of it the next day. Like I loved Māori last year - it was one of my favourite subjects - and I came here and I felt so uncomfortable that I came home and I said to Mum "I don't want to do Māori anymore" and she was like "but you love Māori”.

Q: So tell me how you were feeling and maybe why you were feeling that way?

Well I got lost and showed up about quarter of an hour late because I couldn't find the classroom. I got in and I was this blonde girl walking in the classroom and they were like, I swear, I felt like they were all just looking at me and thinking "What are you doing here? You're totally out of place - you're not Māori” and I felt so uncomfortable. I felt like I couldn't be myself there. In the second lesson we were working in partners and I still didn't know any of them and the girl I was working with, I think she was more friendly because I had to work with her. She actually talked to me because we had to work together. I still felt really uncomfortable, like I felt like I couldn't be myself there. But that's probably the only class that I’ve really felt like that.

Bill also spoke of this experience in his own words. He felt sad that she no longer is involved in something she loved so much:

What I heard Marie reporting was that because she was so Pākehā [looking] and new to the class who may well have been together since they were little kids, even at kohanga, she was challenged about not being Māori. That cut her, so she just thought "I won't do that". I did probe a little deeper to see if it was 'personal' but that was as far as she said it went. She just decided that no, she wasn't going to carry on with that. Look, everything else about her schooling and certainly up to that point with Te Reo had been wonderful.

Marie also volunteered a classroom experience that demonstrated the pressure experienced by Māori who look Pākehā to conform to mainstream expectations and beliefs. Although usually a forthright person who isn't normally afraid to speak against the opinions of others, Marie felt she couldn't speak up in this instance. She felt she 
didn’t qualify to represent a Māori voice because she didn’t conform to others' expectations of what a Māori should look like:

In Geography we were talking about Māori the other day - last week or something - it was this huge discussion and I felt and everyone was talking about how, oh, I can't even remember the discussion, but I had opinions about it because I feel that the Māori have every right to be here and they shouldn't have to give up everything, so I felt like I had quite strong opinions but I didn't really feel like I could say them because everyone else would have been like, well what are you thinking saying that kind of thing? So I didn’t really want to say anything because they would've thought that I was kind of like double-standard, like they probably would've thought that I was not Māori but I was sticking up for them and why was I saying that, you should be on our side. So I didn't want to say anything.

Q: So you go a real sense of sides from that?

Look, a lot of people would say that I don't really have a right to because I'm not even that Māori but I'm like "I am! I am!"

By the end of our interview, I thought that reactions from people had led Marie to make a conscious decision not to raise the issue of her Māori identity with her friends at her new school. This point was well established in my mind when her chosen friend for the study had no idea that Marie was of Māori heritage until I had begun the interview process with her. The difficulties experienced by Marie in asserting a Māori identity in the face of preconceived stereotypes and assumptions also seemed to take an emotional toll. She had spoken about these issues with her mother who had told her: "“You should be proud to be Māori. You shouldn't have to be ashamed that you're only a teeny weeny bit Māori and you're blonde and stuff'”.

Marie indicated towards the end of our interview that she would likely continue studying Māori again at another time:

You can't tell that I am Māori, unless you actually look at my family history, or whatever. You wouldn't know unless you found out and so I still want to [study Māori]. I still want to kind of like accept it and, if I can, I would like to study more Māori at University.

So what changed? How can a Māori student have such a passion for the language in one Māori context, and then feel so isolated and intimidated in another Māori context? 
I felt a range of emotions as Marie shared her stories; sadness that she had stopped something that she obviously had a passion for, empathy for her feelings of rejection, as I, too, had experienced the awkwardness of believing that I didn't quite measure up to a cultural standard, and anger that she felt that her voice wasn't authentic enough. Who sets these standards of cultural authenticity? I wondered. Who gets to decide if you are in or out? I thought about the ETP developed by Bishop et al. (2009) and wondered whether teachers who used this to inform their practice were able to consider how best to meet the needs of Marie and Sophie "as Māori” and as culturally located individuals.

After processing the stories of MJ, Lea, Marie, Sophie, Hinemoa and Pare I read further about the nature of forced identities. I began to realise that because they are not identities chosen by the girls, or identities that they have control over, their existence and the impact they make on the girls' sense of self may not be consciously visible to them. This appeared to be a mountain trail that the girls journeyed but that is largely unmapped in research literature that focuses on Māori Education. I began to really question the impact that forced identities had made on these girls' academic achievement.

\section{Fluid Identities: Redefining Passageways}

McIntosh associates Fluid identities with society’s youth as they appear more willing to "play with cultural markers such as language, custom and place and reconfigures them in a way that gives both voice and currency to their social environment ... to articulate a Māori identity that is strongly grounded in its particular social landscape” (McIntosh, 2005, p.46). It is within fluid identities that being Māori in a traditional sense is challenged, as Māori who adopt fluid identities "borrows and transforms many of the fixed elements found in the traditional identity” (McIntosh, 2005, p.47).

Aspects of a fluid identity appeared to surface in each of the high achieving, Māori girls as they each demonstrated an ability to redefine herself to suit the social conditions that were presented at school. For Marie and Sophie, this meant keeping their Māori identities separate from schooling experiences by being Māori with their family. For Lea and MJ, fluid identities emerged through their ability to adapt their traditional Māori identities so they met the expectations of the mainstream schooling community. This fluidity appeared to support these students in their pursuit of academic achievement. 


\section{Hidden identities}

It appeared to me that Marie and Sophie felt more comfortable about leaving their Māori identities at home with their family. They felt it was appropriate and less complicated to celebrate being Māori within these confines. A strong reason for this was that their appearances did not indicate that they were of Māori ethnicity, so questions about their identities were not raised at school and neither of them felt it was necessary to volunteer this information.

For Sophie, the decision to keep her Māori identity isolated from school practices did not appear to be a hard one:

There is opportunity for Māori involvement in school but I don't tend to go towards that. The stuff I do do, I like to do with my family. I would say that for me, personally, that that's right. My Māori heritage does not really overlap with my academic studies. Apart from I feel like a whole line of ancestors behind me, who would want me to do it. Kind of just helping me, but apart from that, I want to make everybody proud, which I would definitely say is a Māori trait from me. I'd say that's right. I haven't integrated my Māori heritage in my academic studies at all. I don’t know what that means.

Q: Do you ever talk about that side of your heritage with your friends?

Yeah, and they're interested and supportive as friends are, but they don't do it themselves, so it's not a relevant part of their life. So we don't do any of that stuff together. It's a family thing.

Richard, Sophie’s friend, discussed how other people reacted upon discovering her Māori heritage: "Quite a lot of people are always surprised to hear "Oh you're part Māori” but for her, she's always kind of known it and it's always been there.”

Later in her interview, Sophie was able to articulate a reason behind why she chose to keep her Māori identity hidden at school. She seemed to express a degree of pride in the fact that what she had accomplished academically could not be attributed to a public perception of her being Māori:

All the work I've done is from me. It's not from people wanting to help me because I'm Māori or people not wanting to help me because I'm Māori. I think I'm quite lucky in that respect.

Q: Why do you think you're lucky? 
When people find out about my Māori heritage, not everybody but just the occasional people just patronise me a little bit more. And that's something I really don’t appreciate. I really don’t like being patronised and I occasionally find I just like being treated like everyone else, same as everyone.

This comment from Sophie demonstrated that she was very aware that identifying yourself as Māori can influence the perceptions that others have of you. She had discerned a noticeable change in attitude from other people as a result of disclosing a connection to her Māori identity. As a result it appeared that for Sophie, academic success - or success in her eyes - aligned with being judged on your own merits, not feeling favoured or benefitting from being perceived as Māori.

Marie had different reasons for choosing to keep her Māori identity hidden at school. The reactions of others to her claim of a Māori identity had influenced her decision to wait until university to pursue her academic interests in Te Reo. Discussions with friends and school peers about her Māori heritage reinforced the message that she couldn't be Māori because she did not fit their ideas of what a Māori student should look like:

No-one thinks I'm Māori, so they just think I'm Pākehā, like you wouldn't know.

Q: So does that affect your ability to want to tell people?

Kind of. Like people, when they find out they're just like "Wow, you're so not Māori," and I'm like "Yes I am". Like my friends, they ask me why I'm doing Māori and I said "Because I am Māori and I really enjoy it" and they're like "No you're not” and I’m like “Excuse me?”

Again, I was forced to wonder to what degree choice was involved in Marie's claims to an identity at school. Was she forced into a position where she had to adopt a Pākehā identity, or did she choose to be viewed as Pākehā because of the negative experiences she has had? It seemed to me that the reactions of others had led her to make a conscious decision not to raise the issue of her Māori identity with her friends at this school when she began as a new student in 2010. Marie and Sophie's stories had also led me to consider, at what point are you forced to follow a path because there are no others to take? 


\section{Movement between cultural worlds}

A characteristic of a fluid identity is that "it also challenges notions of authenticity and lays out new forms of claims making” (McIntosh, 2005, p.47). Although Lea and MJ identified themselves as having a traditional Māori identity, they did discuss schooling experiences that demonstrated an awareness of reacting, or adapting in response to a social environment that was not Māori. In order to succeed outside their Māori classroom and within the mainstream schooling environment they changed aspects of their personality and behaviour. MJ made specific links to achievement and success:

Q: How do you get yourself motivated?

I just have to ignore it, you kind of like have to go to the Pākehā side, to actually... Like that's how I feel 'cos all my friends are Māori at this school, so you kind of like gotta like separate yourself from them sometimes, to see what others think and then that motivates yourself by talking to the teacher.

Q: When you say "go to the Pākehā side"? 'Cos I think I understand what you mean, but can you tell me what you mean?

Talking to more kids that are Pākehā and asking them questions and mostly teachers are not Māori so, you can ask them and talk to them about it.

Q: So are you conscious of that? Do you know yourself that you're switching roles, or you're taking that Pākehā way of learning?

At the start I didn't, like it's just sort of like, oh my gosh, what [did] I do? Then you just, you just notice that you're constantly going to the same kind of people and you're like, not going to the people that you usually hang with, or that you're around most of the time.

While Lea felt strongly about retaining a strong sense of her taha Māori, she acknowledged that moving out of her Māori class and into the mainstream, predominantly Pākehā, environment had some influence in changing aspects of her behaviour. This change was also identified by Pare in her interview. Lea said: “I'm real hori and rugged [in Māori], but less [so] when we come out. I find it easy. I don't find it like "I'm Māori, and you're Pākehā”. I’ve got different cultured friends. I still relate to them still”. She was able to better articulate this change in her behaviour later in the interview:

From like, ManaTu to say another class, like a mainstream class, like Bio or Math or something? I'm more outspoken [in ManaTu], yeah, definitely whereas in the 
other classes I'm quiet and just listen more, do more work and a good student there. I'm still a good student in the other one but [I] speak my mind more.

Listening to the participants tell stories of how the four high achieving Māori girls navigated cultural fluidity within their educational context was not a process that was a complete revelation to me. I already had personal experiences of my own which showed me that the way individuals act, behave and think can by altered by the social environment of that moment. The movement between my own Māori and Pākehā whānau and between many other Māori and Pākehā social contexts had shown me this. Personal experience had also shown me that it can be an unconscious process. I don't remember thinking "now I should be Māori”, or "this is how I must act now" but I do remember feeling as though I was not fully myself at the same time. What I did learn from the experiences relayed by the participants of this study in relation to fluid identities was that there appeared to be a conscious, strategic shift in how the girls positioned their multiple identities. While one identity was suppressed, another was made visible to improve opportunities that enhanced academic achievement. However, as Pare signalled earlier, “act[ing] like someone they're not . . . [and] mak[ing] ourselves fit it" when moving from the Māori room to the mainstream school was not really a matter of choice.

\section{High Achieving Identities}

Although the primary participants of this study were selected based on NCEA results to determine that they are academically successful, it became apparent in their interviews and through the interviews of their caregivers and peers that they were high achieving in many aspects of their lives. It was particularly the discussions with the friends of the high achieving, Māori girls and their parents that allowed me to appreciate their successes in sporting, cultural and musical contexts.

Academic success was just one area of their mainstream schooling in which they did well, and was not necessarily perceived by the participants as the most important aspect. Sophie's friend, Richard, discussed the importance of Sophie's real passion in life, the violin: "She's very involved with music, very driven with her violin. She practises two hours a day, if she can". Karena described Sophie as "kind of high achieving if she wants to be high achieving in everything that she does". He revealed that sometimes academic success took a back seat to other pursuits and passions in which Sophie is engaged: 
I guess the other thing is that she's really busy outside school as well. She plays the violin, she sings and she's got a part time job and she plays badminton. Her problem is actually finding the time to fit all this stuff in. So she sees that particularly the music - she see's that going to a violin lesson, or singing, she sees that as just as important as the stuff she does at school.

Jane also spoke about her daughter's involvement in extra-curricular activities. She believed that the school viewed Lea as an achiever and that this encouraged involvement in other school activities, like the school newsletter. Similar to Karena, she stresses her daughter's willingness to participate and seek out other avenues that provide successful life experiences:

Sporting wise she's having great opportunities and again, I think that's partly about her personality and her personal drive to kind of excel. Like she does quite well in the teams that she participates in. She got invited into the hockey, I think there was probably a lack of players but through her good relationships was given opportunity and has gone on tournaments and things, at quite a high level, quite quickly and again that's because she throws herself in with full commitment. She's creating those opportunities because obviously if you're not sort of shining a little or being seen to participate or being open to those opportunities then they don't come your way quite the same.

Mary spoke about Marie’s willingness to experience all that is on offer:

I think she herself likes to be involved in a lot of stuff; a lot of different stuff. Like she's told me once at University she wants to do... she can’t really decide exactly on what she wants to study, she wants to do heaps and heaps of things, like at once, you know? She says she wants to do Philosophy and all these things.

Hinemoa and The Silver Surfer discussed MJ's sporting successes. The Silver Surfer hinted that MJ's involvement in sport had aided her academic success.

She probably gets more [acknowledgement] from being high achieving not persay because she's a Māori student but more in her sporting, I suppose she gets rewards in terms of Senior A Netball, they go away to tournament. Acknowledgements in assembly perhaps? Through her sporting achievements, that sort of thing? I don't 
know that she's been given any leadership roles, as a consequence. She may well of but not that I'm aware of. . . I s say if she had more of the sports side of it, I think in some ways that would've had more of an impact, perhaps, I don't know, more so than the Māori element, you know. I think that's been an important part for her and it's nice to have it alongside but I just wonder if she had that sporting element. I certainly think, I really believe in the sporting side of things as well. Being, like you say, just breeds that whole sense of achievement and excelling at something.

This comment also raised an interesting point that demonstrated the complexity of identity. How do we really know which of the multiple identities that these Māori girls possess contribute towards successful academic achievement? Can we discover whether one identity is more influential toward attaining academic achievement over others? The Silver Surfer seemed to think that MJ's sporting involvement may have had more impact on her academic achievement that any other influence, including those associated with her Māori identity. If the expression "success breeds success" has any truth to it then perhaps the influence of a high achieving identity should be considered. Success in sporting, cultural or musical contexts may also provide the impetus for high achieving, Māori girls to strive for high academic achievement in an English Medium mainstream schooling environment.

\section{Global Identities}

An identity that was alluded to, rather than explored in any great depth, in this study was a global identity. I have defined this as an identity that appreciates the multicultural context within which communities exist. This identity became visible to me when I re-read and thought about the following comment from MJ:

In Year 11 where I went from a Pākehā-Māori form class to a full Māori class I didn't like it because it's like, you know, they're trying to make Māoris feel special, but at the same time they're pulling us away from our actual world. Like other people in our school that we are friends with and then it makes them kind of have like a negative view, like, we want to keep to ourselves and you guys can't come join. I think that it makes me feel like the lunch times and stuff is the only time I can come out here and I can't stay in there because I'm with them every day. Q: So do you come out of the room at lunchtime?

Yeah I usually come out to the quad 'cos I just get sick of Māoris all the time [laughs]. So I just didn't like that idea because it was pulling us away from our 
other friends. . . I I was like, they might have thought that they were protecting the Māoris and making them feel comfortable, but... nah. . . . I think Māoris need to know what’s happening, kind of Pākehās to understand Māori as well. They can’t just understand Māori without it.

This comment revealed to me that there seemed to be a tension between fostering a strong sense of a traditional Māori identity and wanting to belong to an environment that MJ could appreciate was indicative of a larger, global community. Again, I was forced to wonder about the impact that this identity could have on high academic achievement. Within this English Medium mainstream schooling context, Māori identities were marginalised, as the Pākehā culture dominated the knowledge and power structures. Perhaps having an appreciation and a sense of belonging within a global community aided these high achieving, Māori girls’ in their navigations and contributed towards their high academic achievement?

\section{Taking Stock of the Journey}

As I analysed the interview data, it soon became apparent to me that diverse, multiple identities were forced on these young Māori women at many different times and at various stages of their schooling experiences. Yet despite being marginalised, excluded, or adopting diverse identities, they persisted with academic success.

While the traditional identity was consciously adopted by MJ and Lea, seen as supportive of their academic achievement and visible to them, some were forced, or formed as a response to stereotypes and lay beneath the surface of their consciousness. The traditional identity appeared to empower MJ and Lea and their ability to succeed academically but they were also disempowered by the perceptions, biases and assumptions of some Pākehā people with whom they came in contact in the English Medium mainstream schooling environment.

I thought that aspects of the hidden identity could be seen as fluid or forced. Sophie and Marie conveyed a degree of conscious choice in the adoption of a hidden Māori identity, as they astutely perceived it would support academic success; however the stereotyped assumptions from Pākehā and Māori, based on Sophie and Marie's Pākehā appearances, suggested there was an element of force to this choice because the pressures and perceptions of other people could be overpowering.

The influence of high achieving and global identities on academic success was hinted at in this discussion. To what degree did having an achieving identity (through 
success in sporting, cultural or musical contexts), or a global identity, impact on the motivation of a Māori girl's high academic achievement? I thought that this was a pertinent question that was, unfortunately, outside the scope of this study.

The multiple Māori identities that have been examined in this chapter have represented ways in which these high achieving, Māori girls have navigated diverse routes in an English Medium mainstream schooling context. Through journeying up one, or several of these routes, and at interchangeable times during their schooling careers, these girls have approached the summit of the mountain and academic success. This is a destination that a disproportionate number of unsupported Māori students have been unable to reach.

I can now see that a journey to the mountain top which represents my own research journey is more complex than I could have imagined and will take a little longer. Through this journey, I came to some unexpected and interesting realisations about multiple, Māori identities and their impact on academic achievement. One of the most frustrating is that identities can be self-defining and elusive. McIntosh (2005) aptly states: "Identities, then, by their very nature, are in a state of flux yet there is a tendency to try to apply rigid labels ... [that] respond to, and are shaped and informed by, the socio-political realities in which they are embedded” (McIntosh, 2005, p.39).

I wondered how Māori identities had become so fractured and why this seemed to be unacknowledged in schooling institutions, contemporary research studies and initiatives purporting to serve the needs of Māori students in mainstream education. The high achieving, Māori girls demonstrated in this study that they had never wavered in their resolve of who they were as Māori and as culturally located individuals, but it was clear to me that their mainstream schooling context - and this was likely typical of most English Medium mainstream schooling contexts within Aotearoa - demonstrated only a narrow understanding of how diverse their multiple identities actually were. 


\section{CHAPTER 4 Transcending the Clouds}

This chapter will examine what I have learned from this journey through listening to the narratives of others. I stated at the outset of this thesis that this was a personal journey, but have found that this process also involved thinking and reflecting about my professional role as a teacher. As I developed an understanding of postcolonial theory and related it to the findings in this study, I was able to critique my own teaching practice and theorise how these findings could be incorporated into teaching pedagogy and practice. Later in the chapter, I discuss the limitations of my methodological approach and highlight what I should have done differently during the research process. Finally, I introduce recommendations to researchers, policy makers and educators in light of my findings in this study.

I had thought about how I was going to begin the final chapter of this thesis many times over the course of the writing of it. In the beginning I had imagined myself conquering the metaphorical mountain with some catch-phrase rolling off my tongue that would describe the finality of this moment. "At the peak, looking down", or "Surveying the terrain below" were two such examples that I believed would demonstrate the closure of the journey on which the participants and I had travelled. However, although I have developed new understandings about these high achieving Māori girls' multiple identities, I realise that this research process raised more questions than I could possibly pursue in terms of completing a three paper thesis and that I have only a superficial understanding about these girls’ lives and their multiple identities.

\section{Postcolonial Theory and the Construction of Knowledge}

My most significant learning from this research has been how issues related to multiple identities and tensions experienced by these four Māori girls can be attributed to what Tikly (1999) has termed "the complexities of the post-colonial condition" (p 612). I found that although MOE initiatives, such as Te Kotahitanga and Ka Hikitia, seek to address cultural displacement of Māori, there is real need to further delve into multiple Māori identities to "describe . . . the way that colonialism is understood and narrativised” (Tikly, 1999, p. 605). Tikly (1999) goes on to say that this process “involves going beyond the 'binary oppositions' by means of which colonialism has been studied in the past. . . . this has [in part] been achieved by focusing on the 
“unstable”, "hybrid” and "fractured” nature of colonial and postcolonial identities” (p. 606). Within this study, I came to realise that those Māori identities which were fluid, forced and hidden, have resulted from existing power relationships in our society. Integral to this process are assimilation pressures, where Māori students are expected to confirm to Pākehā norms and values if they wish to be succeed in English Medium mainstream school environments.

I have come to realise that this research methodology has been a powerful professional development tool. I have already begun thinking about the changes that I will make to my teaching practice next year. As an English teacher, I feel it will be important that I choose texts which facilitate discussion about how knowledge is constructed and valued in our society. I want my students to think about the issues raised in this study. In particular, I want them to be able to examine how social, economic and political influences in our society have shaped their own multiple identities. The details of how I will incorporate this new learning into my teaching programme will involve considerable, further thought.

I now believe it is crucial that teachers in Aotearoa develop an understanding of postcolonial theory. This will invite discussion about how relationships between the coloniser and the colonised have evolved and continue to impact on contemporary society, thus making visible existing power structures which inform whose knowledge is valued and perpetuated in a society. This will make teachers question their role in this process and consider the multiple identities of all their students. Banks (2001) argues: "If teachers are to increase learning opportunities for all students, they must be knowledgeable about the social and cultural contexts of teaching and learning” (p. 197).

Although, I have been critical of the work of Bishop (1999), Bishop \& Glynn (2003), Bishop \& Berryman (2006) and Bishop et al. (2009) in relation to the ETP, I must acknowledge that my learning has benefitted from the approach of listening to student narratives, a strategy that was first promoted through the work of Te Kotahitanga (Bishop et al., 2009). While Te Kotahitanga has measured success by promoting cultural responsiveness and listening to the voices of Māori students, the findings of this study point to some limitations. First, Te Kotahitanga does not give me confidence about how to care for Māori students as culturally located individuals because it does not consider those Māori identities that are fluid, forced, hidden, high achieving, global or other. Second, this initiative does not ask teachers to think about how historical conditions have shaped the way knowledge is constructed and perpetuated within their own classrooms. 
I propose that if English Medium teachers in Aotearoa engage in professional learning which enables them to think about the "legacy of colonialism” (Loomba, 1998, cited in Tikly, 1999, p.605) they could begin to address inequities that exist within their classroom, school and society. This professional development could look like a journey that is similar to the one I have experienced, where knowledge is constructed collaboratively with students and caregivers, or it could involve workshops about the fragmented state of Māori identities and how this affects schooling experience and academic achievement. What follows is a presentation of my own personal learning, co-constructed with the stories of the 12 other participants from this study. I would envisage that a teaching professional development programme that sought to educate about postcolonial theory and knowledge construction incorporate these findings.

\section{Identities as fluid, social constructs}

I don’t really, like, see myself as a "high achieving, Māori” sort of because I'm not the brainiest person, you know. Like, there's all the people in our school, there's like, higher. I'm like probably average in this school, so I don't really see myself, just because like I'm one of the highest Māori, I don't really see myself as like a high achieving, Māori student.

Q: Do you never think of yourself, in terms of being Māori, as doing well at school?

Yeah, I guess because heaps of my - this is bad - but my family and, like, other friends I know, I guess I do achieve more than they do. (Lea)

I have taken this snap-shot of my interview with Lea to demonstrate that a key idea I learnt from this study was that identity is a social construct. The discussion and feedback generated by all the participants of this study demonstrated that the four high achieving, Māori girls were able to "redefine the social identities that had been ascribed to them in ways that were consistent with their own sense of the meaning of their social locations” (Cole \& Luna, 2010, p. 77). This is consistent with the definition of identity I posed in the methodology chapter which stated that an identity is formed by "nam[ing] itself in particular ways in relation to other social categories or classifications" (Stets \& Burke, 2000, p. 224). This finding also challenges the understanding of Māori identity as discussed by Ka Hikitia (2009): "Succeeding as Māori captures and reflects that identity and culture are essential ingredients of success” (p. 18). In this study, it could be seen that these four young Māori women realised academic success at different times 
and in various ways through manipulating their multiple identities. For them, "Succeeding as Māori” involved suppression of their culture and identity in order to blend in with the Pākehā majority. This appeared to be, in part, a conscious process, as the girls described an ability to shift identities according to their social environments. For Sophie and Marie, this meant being perceived as Pākehā at school and acknowledging a Māori identity outside this context. For Lea and MJ, it was natural to embrace a traditional Māori identity within the context of the Māori classroom, but when they moved into the mainstream schooling environment they acknowledged that adopting elements of a Pākehā identity was necessary for academic achievement.

Consciously choosing to change identities to suit social situations was a theme that was prevalent in other literature that discussed identity theory. Choudhry (2010) conducted a study that explored the identity of South Asian and white interethnic adolescents. He discusses in depth those participants in his study who had developed a situational identity. He describes them as individuals who were able to change or emphasise an ethnic identity depending on the social context and what suited them most: "It appeared that individuals were constantly negotiating their identities; they present one identity as more salient than another depending on their social context and personal goal” (p. 129). For three of the high achieving, Māori girls of this study, changing or shifting identities appeared to support the maintenance of academic achievement within their mainstream school. Sophie felt that she was lucky to be perceived as Pākehā at school because it enabled her to be judged on her own merits, rather than be judged as Māori. MJ spoke about "going to the Pākehā side" to support her learning and Lea thought she did adapt her behaviour somewhat when moving from a Māori context to a mainstream environment. It seemed that although Marie could not identify any direct academic benefits from her shift in identity, being perceived as Pākehā at school stopped the criticism she had received about her ethnic heritage and perhaps allowed her to enjoy school more. However, a negative consequence of this was that she decided to discontinue studying Te Reo Māori - a subject she had studied at her previous school and excelled in. This aligned with Choudhry's (2010) discussion about positioning, as he found in his study that "the young [research participants] were influenced by others positioning of them and negotiated their own positions with regard to identity" (p. 176).

Although motivation for the girls' fluid and forced identities appeared to be grounded in perpetuating academic achievement within their English Medium mainstream schooling environment, Hohepa (n.d.) argues that in Māori Medium 
education "there is not an either/or choice between language and cultural achievement and educational achievement” (p. 2). Sleeter (2011) states that people are forced into identities to satisfy the need to belong. Therefore, Sophie, Marie, Lea and MJ may not have been able to succeed so well academically in an English Medium mainstream environment without making concessions to their Māori identities.

The paths that the high achieving, Māori girls from this research study have travelled demonstrate that there are many ways to be Māori in contemporary society. Hynds (2007) cited Durie (2005) who acknowledges that the development of Māori identity and culture is a fluid and changing process:

Being Māori will not necessarily hinge on conformity to a preconceived or classical notion of Māori-ness or on stereotypes derived from socio-economic indicators, but on access to te ao Māori and opportunities to participate in the richness of that world...Te ao Māori, the Māori world, is not static nor is it a pristine memorial to the past. While some of its features, such as the land, rivers, and even the sea, have survived the threats of time, their significance and their relationship to whānau has been shaped by modern understandings and experience of environment. Similarly, although a 'corpus of basic convictions about reality and life' has remained relatively constant, the manifestations of culture are subject to flux, so that change becomes the norm....Being Māori in the third millennium will not be the same as it was a thousand years earlier, but nor will it be the same as not being Māori. (Durie, 2005, pp. 3-5)

The works of Tikly (1999), Banks (2009) and Sleeter (2011) have helped me to understand that the traditional, forced and fluid identities expressed by MJ, Lea, Marie and Sophie are a product of a continued form of assimilation. Banks (2009) articulates that assimilation was initially seen as desirable for many ethnic communities who had experienced the Western colonisation process. However, over time they were exposed to discrimination and racism and began to understand that they would not receive the same benefits as the dominant groups. Ethnic groups then began demanding the right to retain their culture, language and other important ethnic characteristics (p. 104). In Aotearoa, government policy officially promoted assimilation policies until the 1960s, when the Tino Rangatiratanga movement began. To combat a united Māori voice, the government adopted biculturalism in the 1980s and it has been argued that this political movement enabled them to "sell their old assimilatory policies under a new label" (Drichel, 2001, p. 209). This enabled me to see how English Medium mainstream 
school initiatives, established to support Māori students, unwittingly become a tool that perpetuates Pākehā cultural dominance because they fail to challenge power structures.

The challenge for present and future researchers, schools, teachers and policymakers is to convey an understanding of fluid, Māori identities in work associated with Māori Education. This could be achieved by showing students how knowledge is constructed and valued in education and society. This process would involve teaching students that fluid, or lost Māori identities are not mutually created between Māori and Pākehā, but that they are forced constructions indicative of the dominance of Pākehā norms and values.

\section{Identities and stereotypes}

As mentioned in chapter 2, I had given the girls a socially constructed identity that represented a common ground they all shared. For the purposes of this study I labelled them as "high achieving, Māori girls”. However, as Lea aptly pointed out, I had defined the girls in ways in which they didn't necessarily view themselves: “Just because I'm one of the highest achieving Māori [in this school] I don’t really see myself as a high achieving Māori student”. By doing this, I have demonstrated that not all identities are chosen; possession of a social identity can be an unconscious process that is imposed upon an individual by others in society (McIntosh, 2005). Labels, assumptions and stereotypes seemed to be a constant struggle and prevailing tension for these girls and how they expressed their Māori identity at school. Lea and MJ present a visible traditional Māori identity at school and as such, experienced racist and stereotyped attitudes from peers based on their negative perceptions of what it meant to be Māori.

While most of the participants could identify barriers erected by the stereotypes and assumptions of others, the impact of these on participants may have caused them unconsciously to decide not to express an identity. It appeared that Sophie and Lea had made a subconscious decision not to reveal their Māori identity within the schooling context as this would generate negative backlash that they would rather avoid. In his study Choudhry (2010) found that physical appearance, more than any other aspect, was a significant influencing factor that determined an adolescent's formation of their identity (p. 175). This finding clearly did align with Sophie and Lea's schooling experiences but I later realised that it had not influenced MJ's decision to identify herself confidently as Māori at school. She also has a fair complexion and could plausibly be perceived as Pākehā too but did not describe any experiences of discrimination based on her appearance. 
The works of Tikly (1999) and Banks (2009) indicate how teachers can address power relationships in the classroom. Tikly (1999) discusses how racial stereotypes of indigenous groups were constructed in text books and "served to legitimize the economic exploitation of the colonised” (p. 611). He argued that deepening our understanding of how different groups are constructed in school curriculum, textbooks and the policy discourses of contemporary society would enable us to see how dominant groups are able to legitimise their control, and perpetuate the stereotypes and inequalities, experienced by other groups through education systems (p. 612).

Banks (2009) reiterated this point by claiming that "multicultural citizenship education” would help to dispel racial stereotypes by encouraging schools and students to think about the home and community cultures of other students. He claimed this would help them to develop a critical consciousness of their home and community cultures (pp. 106-107). This could be achieved, in part, by using the curriculum to help students understand "that knowledge is socially constructed and reflects researchers' personal experiences as well as the social, political, and economic contexts in which they live and work” (Banks et al., 2001, p. 198).

\section{Māori identities and exclusion}

Another important factor discussed by Choudhry (2010) that contributed to identity formation was the importance of acceptance and rejection within social groupings. He found that individuals tended to adopt the identity of the ethnic group from whom they received the most acceptance (p. 176). This ability to belong to one group or the other was based on visible appearance and the demonstration of an intimate knowledge of the social protocols and idiosyncrasies of that culture (p. 130). The traditional Māori identity that McIntosh (2005) introduced also discussed protocols that foster a sense of belonging to those who meet the criteria. She stated that a traditional identity values knowledge of Te Reo and tikanga as evidence of passing as an authentic Māori. However, she also cautioned that this produces rigid expectations about cultural content, thereby alienating Māori who may not have access to cultural resources, or allow for cultural evolution (p. 45). When Marie Granger was introduced to her new Māori classroom at this school, she clearly felt she did not belong. Were they feelings of rejection from the established classroom culture that she had experienced? Was her appearance deemed too fair for her to pass as Māori in this context? Or was the established classroom culture so different to her previous school and what she had understood was a Māori context for learning, thereby making the situation 
uncomfortable for her? During our interview she spoke about her Māori class in the previous school she had come from. Half the class had been Pākehā students, with no Māori heritage. She felt that although most of them had no prior knowledge of Māori, they were all accepting of one another, and this helped the class to bond.

Marie's experiences supported me in seeing how assumptions and stereotypes are formed and relayed within an ethnic group. "Traditional identities have many inclusionary mechanisms that allow Māori to find a valued place for themselves but they also create space for some exclusionary mechanisms” (McIntosh, 2005, p.44). Therefore, if a culture had been established in this classroom and Marie was unaware of the social protocols and idiosyncrasies, she risked being excluded from that environment. I thought about the implications of Māori identities and exclusionary mechanisms in literature that discusses culturally responsive pedagogies for Māori students. An important aim of Te Kotahitanga (Bishop et al., 2009) was to investigate how teachers could develop culturally responsive pedagogies in mainstream secondary classrooms and improve the educational achievement of their Māori students. From this study, the Effective Teaching Profile (ETP) was developed, where teachers are expected to demonstrate on a daily basis "that they care for students as culturally-located individuals as Māori” (p. 735), yet there is little explicit attention to issues related to lost, forced or other identities. I thought about the diverse Māori identities that I could detect in this study and I felt that the ETP painted a very superficial picture of Māori students who are being educated in many English Medium mainstream educational classrooms. I could understand how this could benefit some Māori students who had a traditional Māori identity, but I was concerned about the significance of the ETP in light of the multiple identities expressed by these four high achieving, Māori girls and the dilemmas they faced. What message was this sending to English Medium mainstream teachers about how they approach the education of Māori students?

Mainstream school environments in Aotearoa exist within unique social contexts that are determined by a range of social constructs and measurements (including diverse economic settings, gender and ethnic disparities). If identity formation is determined by social context, then the ability to belong and experience acceptance or rejection can be quite a localised process - perhaps as localised as different Māori classrooms in different mainstream schooling contexts. Our society may now need to acknowledge that being Māori may look different within different schools and their communities. 


\section{The tension between Māori identities and high achieving identities}

I return to Lea's comment because it also highlights another key issue. In this study, contradictory beliefs were expressed by participants about what constituted success and achievement for Māori students and how this was best facilitated.

I was interested in the different expectations of a secondary school education that the parents of this study expressed for their daughters and the complexities of defining achievement for Māori as a homogenous ethnic group. Jane was a great advocate for ManaTu, as the values that the programme promoted aligned with the education she valued for her daughter. For her, successful education was holistic in nature and would prepare her daughter to have "the confidence to contribute . . . [in a] wide range of cultural contexts”. However, the Silver Surfer wanted ManaTu to demonstrate further connections to the mainstream curriculum, so it had more pragmatic value for her daughter and her ability to function in society upon leaving secondary school. She voiced regret at not planning MJ's option classes more carefully as a student in Year 9 and 10. MJ had taken on Economics as a senior student, but had missed some of the foundational learning because she had been involved with ManaTu. The Silver Surfer saw more value in Economics, than ManaTu, as a subject that would be of benefit to MJ after secondary school. Her values were revealed by this comment: “To us you've got to survive in a White Man's World, first and foremost but also you have your tikanga and that, that's all well and good [but] you've got to have some other subjects there that are going to really drive what you do".

As I went through the data I was surprised by the diverse opinions expressed by participants about how these high achieving Māori girls learned and considered the implications of a one-model-fits-all package that is promoted through culturally responsive pedagogies. The Silver Surfer explained how the Tuakana-Teina strategy, implemented in the Māori initiative, was not helping her daugher's achievement:

In ManaTu she was really disappointed in that last year because it wasn't evolving and growing. You know, the girls probably feel from like Year 9, that they really haven't, they may well feel like they haven't really grown much. It's just boring, it’s just the same, she was just sick of covering Treaty of Waitangi - I don't know how many times - and also she feels that they're always brought down to the Teina level, to support the Teina and I said well that's all well and good but you're not there to totally support the Teina, you're there for your own development as well and I said there's areas where you have to be quite selfish. 
In contrast, Jane spoke positively about how ManaTu fostered ways of learning that appear to be conducive for her daughter:

I think she's a communal learner. I think that goes with being comfortable in a Māori context and so loves to do Mahi-a-roopu with being co-operative as opposed to, you know, you've got your independent thing but I do think that probably they do best when they're given those opportunities to do things in groups, or in pairs, as opposed to independently being the expected norm. That relates to the TuakanaTeina as well. She can give support to others, or she can receive it from others. Probably one of the differences might be that their ways [University/academic environments] of learning are less collaborative, are more individual focussed are more, that might be making an assumption but I tend to think of ManaTu, holistic, whakawhanaungatanga model more, Tuakana-Teina all that that it's actually much more about collaboration and supporting each other and doing things in a cooperative kind of way as opposed to sorting yourself out and being really individual in your approach to things might be a difference.

It seemed to me that although there are established beliefs about pedagogies that have been shown to support Māori learners, we also need to recognise that diversity within Māori ethnicity can arise from the other identities that Māori students possess. Jane identified Lea as a communal learner, but she had also discussed her ability to selfmanage and motivate herself to learn at other times during our interview. Comments from eight participants of this study demonstrated that a characteristic important to the academic success of the four high achieving Māori girls was that they had developed a degree of independence about what and how they learned.

Other inconsistencies in the data also seemed to exist about around the kinds of support that benefitted the achievement of the high achieving Māori girls. During their interviews Lea, MJ, their Mothers and their friends had acknowledged the efforts the school had gone to in ensuring that they were in classes with their Māori peers. While Pare and Hinemoa had felt that this was a strategy designed to support Māori students, Lea, MJ and Marie acknowledged that having your friends in your class could be a distraction. The Silver Surfer was pragmatic about grouping Māori students together: "It can be good having more Māori friends, or Māori people in your class, but I suppose it really comes down to what they do in class”. 
The diverse and contradictory comments expressed by participants about how those high achieving, Māori girls who foster a traditional Māori identity learn, demonstrated to me that there is a potential risk of stereotyping the way all Māori students learn if assumptions are made about a homogenous Māori identity. Culturally responsive pedagogies presuppose that there is "a Māori way" of learning, when in fact this study suggests that adolescent students possess multiple identities and these may directly affect, influence or encourage different ways of learning. Academically high achieving Māori students may learn in ways that align with academically high achieving students rather than Māori students. The influence of a high achieving identity on the academic performance of high achieving Māori students in a mainstream schooling environment appeared unexplored in academic research or literature or acknowledged within the schooling context of this study. A point that was acknowledged by The Silver Surfer: "I see that [MJ] gets to do things because she's in ManaTu, not because she’s a high achieving, female student”.

The pseudonyms adopted by two of the high achieving, Māori girls also seemed to indicate that girls saw themselves in ways that were additional to being Māori. "MJ" stands for Michael Jordan, a famous American basketballer, which demonstrates the influence of a sporting identity and "Sophie" is an online internet cyber pseudonym that she used for discussion forums, perhaps indicating an identity which allowed for social commentary within this context.

Tikly (1999) believes that within schooling institutions there is a need to challenge the underlying norms and values embedded in the colonial, European culture in order to show how some forms of knowledge are made official and others not. He cited the dangers of Māori initiatives that: "substitute[e] one conception of reality and 'truth' with another, non-European view” (p. 614), as this falsely assumes, there is one representation of reality. He suggests that a more progressive path would be the development of a curriculum that acknowledges the existence of a transcultural mixing in which "the boundaries between cultural forms and identities are fluid rather than fixed” (p. 613). This process would show how some forms of knowledge are made "official” and others not (p. 615), which is a course of action that has also been argued by Banks (2009) and Banks et al. (2001). 


\section{The Challenge and Complexity of Researching Identity}

My research journey has been like any journey that is undertaken for the first time. It is only upon nearing your destination that your eyes are opened to more meaningful pathways that you could have travelled. I also discovered whether those pathways I had chosen to avoid at the outset of the study had been done so with due justification, or if they did warrant being journeyed.

\section{Limitations of the study}

First I need to acknowledge that the small number of participants of this study means that it is not possible to generalise these findings and apply them to other high achieving, Māori girls. This has been both a personal journey for them and for myself. Additionally, the stories that have been told reflect a unique time in their lives and they are simply snapshots of their schooling experiences from when the interview had taken place.

The interview questions used in this study encouraged a lot of discussion from participants about the educational experiences of the high achieving, Māori girls and less explicit feedback about identities. It wasn't until I had transcribed all the interview data and had begun analysing it that I realised that those areas of participants' stories which alluded to multiple identities and their associated tensions were the stories that needed telling. Consequently, if I had had more time I would have conducted a second full interview with participants, which would have asked further probing questions about issues to do with identity, motivation and gender. These questions would have been informed by the literature I read during the writing of the thesis, as it has led me to deepen my understanding of key concepts of Māori girls' multiple identities. A further line of questioning could be based around presenting the multiple identities I had identified in each girl and asking each about how these identities have affected her motivation and academic achievement.

Prior to the interview process I believed that the discussion generated by participants could be neatly processed into categories that would clearly define the girls' unique identities and tensions. However, the data was fluid and contradictory and showed me that tensions and different identities are inter-twined.

Some high achieving, Māori girls’ identities have been clearly visible, others less visible. The reasons for this were also complex can be attributed to the residual effects of colonisation on Māori identity formation and the influence of the social condition that perpetuate the dominance of Pākehā culture, in English Medium 
mainstream schooling environments. In her article, McIntosh (2005) claims: "That some identities are more clearly marked than others signals that identity formation is a political process, meaning that while some identities are more clearly insider selfexpressions, others are imposed by outsiders or created in conditions of scarcity or constraint and become expressions of resistance or desperation.” (p.39) In my study, Lea and MJ appeared very staunch about their Māoritanga and felt that participating in ManaTu showed that they were passionate about being Māori. However, this participation also exposed them to forced identities from some Pākehā peers. Sophie and Marie’s decision to hide their Māori identity from their peers at school seemed in part due to stereotypes about their appearances.

The discovery of this hidden aspect of identity has led me to realise that there may have been aspects of these girls' identities that were hidden, or invisible from me. Penetito (2010) draws on a quotation from Achebe to make his point about the fickle and elusive nature of identity: "You can suddenly become aware of an identity which you have been suffering from for a long time without knowing” (p. 44). My realisation of locating a global identity was based on the comment of one participant in this study, but who knows how many more I failed to mention. Perhaps I have been mistaken in combining the sporting, cultural and musical achievements of the high achieving, Māori girls under high achieving identities in the previous chapter and should have labelled each of these as a single identity. There seems to be a wide range of possibilities of what could be considered an identity. Following this logic, it can be seen how current research and Ministry of Education initiatives, like Te Kotahitanga and Ka Hikitia, have conveyed a superficial understanding of the multiple identities that Māori students possess. I hope I have also made it clear that this study has only scaled the mountain as far as the initial cloud cover on this issue. Aspiring to reach the summit will require more time to engage in much deeper exploration of multiple identities of these students.

\section{Ignored paths}

There were aspects of my research that I introduced at the outset of this research study, but didn't explore at all. Although I identified the primary participants of this study by the common ground they shared as high achieving, Māori girls, I did not question any of the participants explicitly about issues to do with the female identity. For a female Māori researcher writing about female Māori participants this could be perceived as odd, and perhaps this demonstrated that I was blinded by my own biases. However, this research project does contribute to our understanding of a Māori female identity because 
its stories are centred on female Māori perspectives. Waitere and Johnston (2009) discuss a need for Mana Wahine to develop more spaces in institutional contexts. They argue that Māori female discourse has been silenced by the process of colonisation and that "Māori women have been defined through the discourses, experiences and realities of Pākehā women” (p. 27). This study contributes the development of a Māori feminist perspective that is distinct from Pākehā women because these stories tell of issues of identity and tensions that Pākehā girls have not had to consider within the mainstream educational system.

My view of high achievement for Māori was challenged by several participants of the study.

I suppose because you've focussed around the academic is what trips me up. . . . It depends on the context of where they're achieving and what sort of environment they're in because obviously a high achieving, Pākehā girl might not look like she's academically better if she's in a Māori context. . . . I'm not so great about the whole academic thing, I mean, I don't put my head there that much. (Jane, Mother of Lea)

I do acknowledge that there are other measurements of success which are as important as those measured by academic means for Māori students, their families and peers, but these are outside the scope of this study.

\section{Forgotten and lost paths}

There was also a large body of literature about motivation that I have not delved into. The intersection of gender, indigeneity and special/gifted abilities is unknown within this story. These were important paths that I would like to have followed, but I did not have the foresight to address them properly at the time the interviews were conducted and analysed.

A reading I discovered after the interview process raised new questions for me about the motivation of these girls in their drive to be academically high achieving. Steele (2004) discusses the impact of stereotype threat; the social-psychological threat that arises when one is in a situation or doing something for which a negative stereotype about one's group applies (p. 683). Steele proposes that stereotype threat is felt most keenly by students who identify with good school achievement. It can pressure disidentification with school as an achiever by undermining sustained motivation. In 
this study, according to Steele's propositions, MJ and Lea would feel this threat most keenly because they conveyed traditional Māori and high achieving identities. Further questions directed to them about how they have managed to sustain their motivation as academic high achievers and deal with the pressures that result from stereotype threat could have been raised. Māori initiatives focussed on improving Māori achievement in schools, like Ka Hikitia and Te Kotahitanga, direct their intervention towards Year 9 and 10 Māori students. If these are the years where, for many Māori students, disidentification with school as an achiever occurs, how did Lea and MJ manage to sustain their traditional Māori and high achieving identities? Steele (2004) cites the danger of focussing "belongingness” on social aspects; a mistake often made by schools through adopting a strategy for students who are part of a stereotype-threatened group, which assumes weak identification with school, poor skills and little confidence (p.694). A danger exists in mainstream schools to encourage a sense of belongingness based on ethnicity and culture, at the expense of instilling an identity of achievement. Perhaps delving further into the stories of Lea and MJ and exploring the forgotten pathway of motivation would help to test this hypothesis.

At the outset of this journey I positioned myself as a culturally located being by making a claim to my Māori identity, but I acknowledged the influence of a predominantly Pākehā upbringing. This influence has restricted my understanding of Te Ao Māori and I can only hold a very basic conversation in Te Reo Māori. The pathways that could have allowed me to learn and develop my knowledge of Te Ao Māori and Te Reo Māori were lost as I was growing up. There was no opportunity for me at school to learn this and the loss of my father at a young age made it more difficult to access the knowledge through my whanau. I have no idea how my lack of understanding in these areas may have influenced the analysis of data, but I am sure that personal biases have played some part.

The lost pathway that has been somewhat reflected in my circumstances is not an uncommon one for a significant number of Māori in today's society. The 2006 census found that 643977 people who lived in New Zealand claimed to be of Māori descent, however 102366 did not even know who their iwi were. ${ }^{11}$ I believe that this “lost” Māori identity commands further examination in research. I return again to Durie (2005): "Being Māori will not necessarily hinge on conformity to a preconceived or classical notion of Māori-ness or on stereotypes derived from socio-economic

\footnotetext{
${ }^{11}$ Taken from http://www.stats.govt.nz/Census/2006CensusHomePage/QuickStats/quickstats-about-asubject/Māori/Māori-descent-and-iwi-ko-nga-kawai-whakaheke-Māori-me-nga-iwi.aspx
} 
indicators, but on access to te ao Māori and opportunities to participate in the richness of that world" (p.4, my italics). If the ability to whakapapa is lost to 16 per cent of people who are of Māori descent in Aotearoa, then they have likely lost the ability to pass on any knowledge of their cultural heritage. Is it not then the responsibility of schools, researchers and policymakers to provide access and opportunities of Te Ao Māori that are inclusive of all the diverse, multiple Māori identities that exist in contemporary society?

\section{In Pursuit of the Summit: Recommendations for Researchers, Policymakers and Practice.}

\section{Recommendations for researchers:}

Sustained research is further needed to delve more deeply into the multiple identities of Māori students. This study has focussed on academically high achieving, Māori girls in order to provide a focus for this three-paper thesis. However, the study has shown that there currently exists a dearth of research that acknowledges multiple Māori identities and the impact that these have on the schooling experiences of Māori students.

Important avenues of exploration were not investigated due to time and planning constraints. Further research that investigates motivation, gender, indigeneity and special/gifted abilities would help develop a more comprehensive overview of the multiple identities and tensions associated with Māori girls' high academic achievement.

In the interviews, some participants made contradictory comments about what contributed to the academic success of high achieving, Māori girls. This tension appeared to arise from the influence of high achieving and traditional Māori identities, as misunderstandings existed about how best to meet their academic needs within a learning environment. Investigation of the interplay between multiple Māori identities may give some indication of why and how high achieving Māori students achieve academically in an English Medium mainstream environment.

\section{Recommendations for policymakers: Ministry of Education}

Future initiatives released by the Ministry that purport to support Māori achievement in English Medium mainstream schooling environments need to take into account the diverse range of multiple Māori identities that exist in our society today. 
Ka Hikitia (2009) is the latest Ministry strategy which aims to improve the educational experience for Māori. The signature phrase that captures the essence of this document is Màori enjoying education success as Māori. However, this study has demonstrated that this is a vague and superficial statement, which implies "a Māori identity" without recognising the influence of multiple Māori identities. I have shown that there are various ways of enjoying education success as Māori, many of which are informed by the influence of hidden, fluid, lost, forced or other identities. This is an area that appears unacknowledged and unexplored in Ka Hikitia and subsequent Ministry initiatives to date.

For positive transformative change to occur for Māori within the mainstream educational system, society's eyes must be open to this diversity. Cole and Luna (2010) have demonstrated how feminist theory has gone some way in achieving social change through this process: “Cohen’s narrative highlights the ways that activists' political work and theory building challenges those who might assume that collective identities are essential, fixed, or ascribed and demonstrates the creative ways identity may be used to generate social change” (p. 81). Academics in Aotearoa have begun theorising about how acknowledgement of multiple Māori identities may benefit Māori learners. Hynds (forthcoming) cited Penetito (2010b) who argues that "the degree of solidarity as a 'moral imperative' is closely linked to how much diversity and difference is accepted and valued within local Māori communities. One challenge to the development of solidarity between mainstream schools and their local Māori communities lies in the acceptance of diverse Māori identities” (p. 19). The Ministry should seek to redress their understanding of the diverse nature of Māori students who are being educated in contemporary English Medium schooling institutions

\section{Recommendations for practice}

It is paramount that English Medium mainstream schools in Aotearoa have an understanding of what being Māori entails within their localised schooling context. This would involve recognition of the multiple identities that the students within their schooling context possess and some thought around how these identities impact on students' achievement. Te Kotahitanga (Bishop et al., 2009) has provided some exciting inroads into the way teachers and schooling communities think about their how their Māori students learn, but the ETP does not encourage teachers to think about what impact multiple Māori identities might have on successful academic achievement, or how to address them in their teaching programmes. If classrooms were really creating 
culturally appropriate and responsive contexts for learning in their classroom and care for their students "as Māori”, as Te Kotahitanga purports to do, there would be acknowledgement of all the identities that Māori students bring in to their classroom; traditional, fluid, hidden, forced, lost, high achieving, global and other.

As I have discussed, the pragmatic implications of acknowledging and supporting multiple Māori identities in the classroom are not as daunting as they might seem. Teachers could engage in professional learning that is similar to the journey I have experienced, or undertake a professional development programme that incorporates the findings of this thesis. I have mentioned the arguments of Tikly (1999), Banks (2009) and Banks et al. (2001), who believe that schools should be teaching the dynamics of knowledge construction and how dominant groups maintain power and control in a post-colonial society. By educating students to map the impact of colonisation, issues such as assimilation, racial discrimination, stereotypes and identity formation can be addressed. This has positive implications not only for Māori students, but all students within Aotearoa, as the social conditions of contemporary society take on new relevance and meaning for them. Banks (2009) states that:

Schools should help students to understand how cultural, national, regional, and global identifications are interrelated, complex, and evolving. These identifications are interactive and interrelated in a dynamic way. Each should be recognized, valued, publicly affirmed, and thoughtfully examined in schools. Students should be encouraged to critically examine their identifications and commitments and to understand the complex ways in which they are interrelated and constructed. (p. 108)

Although researchers such as Banks (2009) and Steele (2004) have not conducted research with indigenous communities, their theoretical stand points are still valid because the issues surrounding multiple, diverse identities are the same. The processes they suggest enable teachers and educators to address the power dynamics that play out in contemporary English Medium mainstream classrooms in an honest and direct way.

There has been a localised study in Aotearoa that has recognised a need to address knowledge construction in the classrooms to improve Māori academic achievement. Kidman, Abrams and McRae (2011) conducted research that focussed on the issue of Māori students achieving at lower rates in Science than non-Māori children, in both English-medium and Māori-medium language settings. They found that while Māori students identify strongly with their culture and the ability to speak Te Reo in 
classrooms, they do not feel a sense of belonging within the science domain. They also argue that an exploration of the "knowledge-power relations that surround indigenous schooling communities” (p. 204) is needed to address this disparity.

\section{Māori Girls and their Multiple Identities: A Call to Continue the Journey}

The feelings I experienced as my journey came to a close were bittersweet. I was pleased to have finished the challenging process of writing, but I felt dissatisfied by the outcome of the climb. I had barely risen above the initial mist which covered this mountain, and I still had no idea how much travelling would be needed to reach the summit. Should the summit be the goal? For many iwi, the top of maunga are considered tapu, or sacred; the dominion of spirits and a place of burial for the dead. Some Māori communities believe that mountains are manifestations of their ancestors, and that the top of mountains should not be scaled. I call again on Durie (2005), who states:

Te ao Māori, the Māori world, is not static nor is it a pristine memorial to the past. While some of its features, such as the land, rivers, and even the sea, have survived the threats of time, their significance and their relationship to whānau has been shaped by modern understandings and experience of environment. Similarly, although a 'corpus of basic convictions about reality and life' has remained relatively constant, the manifestations of culture are subject to flux, so that change becomes the norm. (p. 3)

I remember my Grandmother telling me about how our tupuna were forced to scale our maunga to escape slaughter during one of Te Rauparaha's war campaigns. They ran to the top of the maunga and prayed for their lives to be spared. Their prayers were answered and from that point onwards, our maunga was given a new name, Moketapu. I have always remembered how Grandmum said that many people knew our maunga by the old name, Maungatapu, but her Mother had told her this story and this was how she knew it to be true. The memory of this moment is engraved in the re-naming of this mountain and a reminder that change and evolution of culture is a natural process.

Whether this research should aspire to reach the summit is not now a question that is important. It appears to me that it is the climb that we need to focus our attention on and not the destination. The paths that these high achieving, Māori girls have travelled in their English Medium mainstream schooling environment society demonstrate that there are many ways to "be Māori". An acknowledgment of the 
existence of multiple Māori identities that exist among contemporary Māori youth by teachers, researchers and policymakers would ensure that they really are catering for the needs of all Māori learners. Additionally, real transparency of the fractured nature of diverse, multiple Māori identities would incorporate an education for all students of Aotearoa that addresses the way knowledge is constructed and perpetuated in a contemporary, post-colonial society. 


\section{Reference list}

Banks, J. A. (2009). Human rights, diversity, and citizenship education. The Educational Forum, 73, 100-110.

Banks, J. A., Cookson, P., Gay, G., Hawley, W. D., Irvine, J. J., Nieto, S., Schofield, J. W. \& Stephan, W. G., (2001). Diversity within unity: Essential principles for teaching and learning in a multicultural society. Phi Delta Kappan, 83(3), 196203.

Bevan-Brown, J. (1993). Special abilities: A Māori persective. Unpublished Masters thesis, Massey University, Palmerston North, New Zealand.

Bevan-Brown, J. (2004). Gifted and talented Māori learners. In D. McAlpine, \& R. Moltzen (Eds.). Gifted and talented New Zealand perspectives. (2nd ed,) (pp. 171-197). Palmerston North: Kanuka Glove Press.

Bevan-Brown, J. (2005). Providing a culturally responsive environment for gifted Māori learners. International Education Journal, 6(2), 150-155.

Bishop, R. (1999). Changing power relations in education: Kaupapa Māori messages for mainstream institutions. In C. McGee \& D. Fraser (Eds.), The professional practice of teaching ( $2^{\text {nd }}$ ed.) (pp. 201-239). Palmerston North: Dunmore.

Bishop, R. \& Glynn, T. (2003). Culture counts: Changing power relations in education. Waikato: Led Books.

Bishop, R. \& Berryman, M. (2006). Culture speaks. Cultural relationships and classroom learning. Wellington: Huia.

Bishop, R., Berryman, M., Cavanagh, T., \& Teddy, L. (2009). Te kotahitanga: Addressing educational disparities facing Māori students in New Zealand. Teaching and Teacher Education, 25(5), 734-742. 
Boon, H. J. (2008). Risk or resilience? What makes a difference? The Australian Educational Researcher, 35(1), 81-102.

Boraman, T. (2005). The myth of passivity: Class struggles against neoliberalism in the 1990s. Red \& Green, 5, 25-48.

Bull, C. (n.d.). Te kauhua phase 2 summary report of the te kauhua Māori mainstream project. Retrieved 6 February, 2011 from: http://tetereauraki.tki.org.nz/TeKauhua/Phase-2/Report-summary

Carkeek, L., Irwin, K., \& Davies, L. (1992). A regional study of the school based factors affecting achievement for Māori girls in immersion, bilingual and mainstream classes, units and schools at primary level in the Wellington region. Retrieved 9 March, 2010 from: http://www.aare.edu.au/92pap/irwid92379.txt

Choudhry, S. (2010). Multifaceted identity of interethnic young people: chameleon identities. Surrey: Ashgate Publishing Limited.

Clandinin, D. J., \& Connelly, F. M. (1994). Personal experience methods. In N. K. Denzin \& Y. S. Lincoln (Eds.), Handbook of qualitative research. pp. 413-427. London: Sage.

Cole, E. \& Luna, Z. (2010). Making coalitions work: Solidarity across difference within US feminism. Feminist Studies 36(1), 71-98.

Courtney, C. (2008, June). Māori in the middle. North \& South, pp. 36-46.

Drichel, S. (2001). Explorations of “Other” identities in the novels of Patricia Grace. In G. Ratcliffe \& G. Turcotte (Eds.), Compr(om)ising post/colonialism(s). pp. 207216. Sydney: Dangaroo Press.

Durie, M. (2005). Ngā tai matatū. Tides of Māori endurance. Melbourne: Oxford University Press. 
Fitzpatrick, K. (2005). Education and hybridity: Māori and Pasifika students’ identity and experiences. Retrieved 13 March, 2010 from: http://www.aare.edu.au/05pap /fit05241.pdf

Grantham, T. (2003). Rocky Jones: Case study of a high achieving Black male’s motivation to participate in gifted classes. Roeper Review 26(4), 208(8).

Hallet, D., Want, S., Chandler, M., Koopman, L., Flores, J., \& Gehrke, E. (2007). Identity in flux: Ethnic self-identification, and school attrition in Canadian Aboriginal youth. Journal of Applied Developmental Psychology 29(1), 62-75.

Hohepa, M. (n.d.). Including Māori medium education in schooling improvement. Retrieved 14 July, 2011 from: http://www.education.auckland.ac.nz /webdav/site/education/shared/about/schools/tchldv/docs/becsi/position-paper-8including-Māori-medium-education-in-schooling-improvement.pdf

Hynds, A. (2007). Navigating unchartered waters: Teachers collaborating across difference: A thesis submitted to the Victoria University of Wellington in fulfilment of the requirements for the degree of Doctor of Philosophy in Education. Victoria University, Wellington.

Hynds, A. (forthcoming). Challenges to the development of solidarity: Working across intersections of power and privilege. In C. Sleeter (ed), Building solidarity across communities of difference in education: International Perspectives. New York: Teachers College Press.

Jenkins, H., Moltzen, R., \& Macfarlane, A. (2004). Embracing Māori giftedness: The dynamics of power, culture and visibility. New Zealand Journal of Educational Studies 39(1), 55-70.

Kidman, J., Abrams, E., \& McRae, H. (2011). Imaginary subjects: school science, indigenous students, and knowledge-power relations. British Journal of Sociology of Education, 32(2), 203-220. 
Macfarlane, A. (2004). Kia hiwa ra! Listen to culture - Māori students' plea to educators. Wellington: New Zealand Council for Educational Research.

Mahuika, R. (2007). Māori gifted and talented education: A review of the literature. Retrieved 13 February, 2011 from: http://ojs.review.mai.ac.nz/index.php/MR/ article/view/36/36

Marie, D., Fergusson, D. M., \& Boden, J. M. (2008). Educational achievement in Māori: The roles of cultural identity and social disadvantage. Australian Journal of Education, 52(2), 183-196.

Matthews, K. \& Jenkins, K. (1999). Whose country is it anyway? The construction of a new identity through schooling for Māori in Aotearoa/New Zealand. History of Education 28(3), 339-350.

McIntosh, T. (2005). Māori identities: Fixed, fluid, forced. In J. H. Liu; T. McCreanor; T. McIntosh; T. Teaiwa (Eds.), New Zealand identities; Departures and destinations. pp. 38-51. Wellington: Victoria University Press.

Ministry of Education (2009). Ka hikitia - Managing for success: The Māori education strategy 2008-2012. Wellington: Learning Media Ltd.

Nash, R. (2001). Models of Māori educational attainment: Beyond the "class” and “ethnicity” debate. Waikato Journal of Education, 7, 23-36.

Penetito, W. (2010). What's Māori about Mãori education? Wellington: Victoria University Press.

Piirto, J. (2002). "Motivation is first - Then they can do anything”: Portrait of an Indian school for the gifted and talented. Gifted Child Quarterly 46(3), 181-192.

Poata-Smith, E. T. A. (2008). The evolution of contemporary Māori protest. Retrieved October 5, 2008 from: http://www.Māorinews.com/writings/paper/other/protest. $\underline{\mathrm{hmtl}}$ 
Rata, E. (2004). Ethnicity, class and the capitulation of the Left. Red \& Green, 4, 13-32

Schwandt, T. A. (2000). Three epistemological stances for qualitative inquiry. Interpretivism, hermeneutics, and social constructionism. In N. K. Denzin \& Y. S. Lincoln (Eds.), Handbook of qualitative research (2nd ed.). pp. 189-214. California: Sage Publications.

Shields, C., Bishop, R., \& Mazawi, A. (2005). Pathologizing practices. The impact of deficit thinking on education. New York: Peter Lang.

Sleeter, C. (2011). Uncovering histories for social justice. A presentation at Victoria University, Wellington.

Smith, L. T. (1999). Decolonizing methodologies; Research and indigenous peoples, Dunedin: University of Otago Press.

Steele, C. M. (2004). A threat in the air: How stereotypes shape intellectual identity and performance. In J. A. Banks \& C. A. McGee Banks (Eds.), Handbook of research on multi-cultural education (2nd ed.). San Francisco: Jossey-Bass.

Stets, J. E. \& Burke, P. J. (2000). Identity theory and social identity theory. Social Psychology Quarterly 63(3), 224-238.

Thrupp, M. (2007). Education's 'inconvenient truth': persistent middle class advantage. An inaugural professorial lecture, School of Education, University of Waikato.

Tikly, L. (1999) Postcolonialism and comparative education. International Review of Education. 45(5/6). 603-621.

Waitere, H. \& Johnston, P. (2009). Echoed silences: In absentia: Mana wahine in institutional contexts. Women's Studies Journal 23(2), 14-31.

Walker, R. (1991). Liberating Māori from educational subjection. Auckland: Research Unit of Māori Education, University of Auckland. 


\section{Appendices}

Appendix A: Relationships between Research Participants
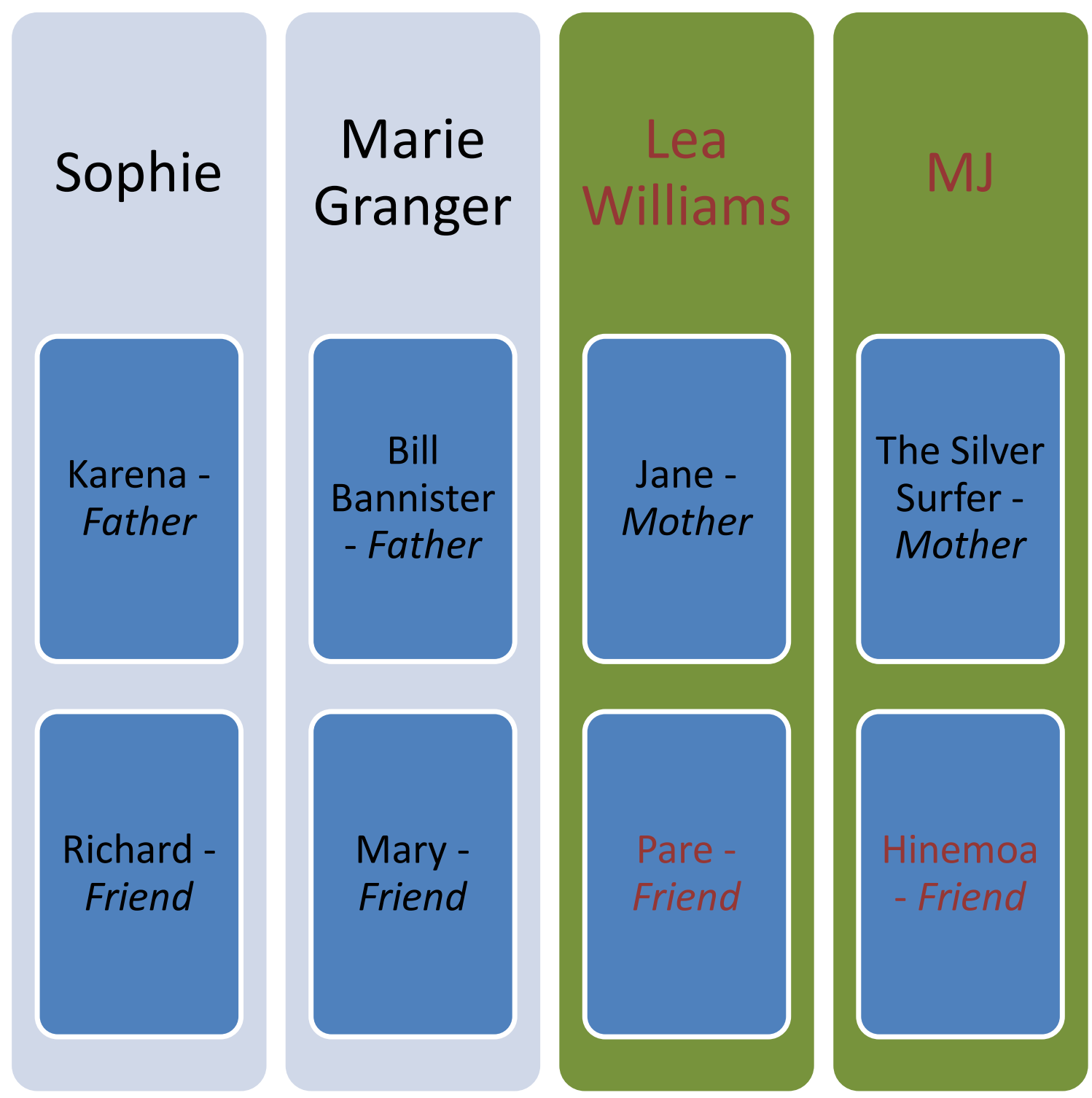

Participants associated with ManaTu

Participants who were very close friends 


\section{Appendix B: Research Participation Information sheet and Consent form}

(VUW letterhead)

Research Participant Information Sheet

PROJECT TITLE:

A case study of the schooling experiences and multiple identities of high achieving, female Māori students who succeed academically in mainstream schooling environments

Tena koe

\section{Introduction and Background}

My name is Liana MacDonald. I am a Masters student from Te Whānau o Ako Pai ki Te Upoko o te Ika a Māui, Faculty of Education, Victoria University of Wellington. As part of my degree I am undertaking a research project leading to a Masters of Education thesis. The University requires that ethics approval be obtained for research projects involving human participants. This information sheet will provide you with information about my research and your possible involvement. It is important that you make an informed decision about whether you want to participate.

\section{Aim of the research}

This case study firstly, aims to investigate how and in what ways high achieving, academically successful, female Māori students succeed in a mainstream schooling environment, and how participants perceive schooling experiences that encourage/discourage their academic success. Secondly, the study aims to explore these students' multiple identities and those that are particularly related to their academic success. Lastly, the study will investigate whether these students face particular tensions in being identified as academically 'high achieving' and 'Māori girls' within mainstream schooling environments. Current research studies of academically successful Māori students in mainstream schooling environments are very limited and this study will contribute greatly to this field of knowledge.

At the present time, learning more about the gap that exists between non-Māori and Māori academic achievement in schools is at the forefront of Ministry of Education research and initiatives. In 2007, statistics showed that only 60 percent of Māori students were meeting NCEA level 1 literacy and numeracy requirements, whereas these requirements were met by nearly 80 percent of non-Māori. In that same year, 44 percent of Māori were leaving school with NCEA level 2 or above, however the figure for non-Māori was 71 percent. Research that focuses on experiences of Māori girls who are succeeding academically in a mainstream schooling environment may provide further insight that can successfully help us understand why this gap exists. 


\section{Volunteers}

I am seeking volunteers to take part in this study. The primary participants will need to meet the following criteria, so the aims of the research study may be met. I will be approaching three students who are:

- Female

- Identify as Māori (this should also be recorded on school records)

- Have achieved a NCEA level 1 or 2 certificate with a Merit or Excellence endorsement in 2009.

The other participants of this study include a parent/caregiver of the primary participants and a close friend/peer of the primary participant. The primary participant can choose the friend/peer who will participate in this study.

If you decide to take part in this study; either as the primary participant, the parent/caregiver or friend, I would like to ask you to sign the consent form attached to this sheet.

\section{What would your involvement mean?}

All participants of this research will be invited to take part in a semi-structured, in-depth interview which will be audio-taped and transcribed. This interview will be approximately 30 - 40 minutes long and will take place at a time and place that suits. Once the interview has been written out you will be sent a copy of your interview for comment.

Please give examples of documents sent by the school (awards, certificates).

\section{Will I be identified in this research?}

No findings that could identify any individual participant will be published. Any reference to individual participants, or to your school, will be by code name, with only me and my supervisor knowing the real names to which the codes refer. If you agree to take part, you can withdraw your consent at any time up until the end of data collection.

\section{What happens to the research data?}

All written material (interview notes, transcripts etc) will be kept in a locked file and access will be restricted to the researchers. All written materials will be destroyed at the conclusion of the research. Any audio recordings will be returned to participants and/or electronically wiped.

Information gained through this research will be used in the writing of my Masters of Education thesis and for publication in academic journals and conferences. I intend to hold a hui upon completion of the thesis (in the latter half of next year) in which the findings of the research will be made available to all research participants.

Thank you for agreeing to take part in this study. Your thoughts are important to me because the study has the potential to contribute to our understanding of what influences Māori students' academic success within mainstream schools. 
If you have any questions about this research, or would like to discuss aspects of it further, please don’t hesitate to contact me via email: liana.m@xtra.co.nz, or phone: 021 2992101.

Yours sincerely

\section{Liana MacDonald}

Should you have any complaint concerning the manner in which this research is conducted, please do not hesitate to contact Dr. Anne Hynds,

Faculty of Education

Victoria University of Wellington

P.O. Box 17-310, WELLINGTON

Email: anne.Hynds@vuw.ac.nz

This research has been assessed and approved by Victoria University Faculty of Education Ethics Committee 
(VUW letterhead)

\section{Research Participant Consent Forms}

\section{PROJECT TITLE:}

A case study of the schooling experiences and multiple identities of high achieving, female Māori students who succeed academically in mainstream schooling environments

I agree to take part in the above research project. I would like to be involved as the primary participant / parent/caregiver participant / friend/peer participant (please circle that which applies). I have had the project explained to me, and I have read the explanatory statement, which I will keep for my records. I understand that agreeing to take part means that I am willing to:

Be interviewed by the researcher

Allow the interviews to be audiotaped

(if applicable) Agree that the researcher can review any documents, reports and /or awards sent to you via the school that are associated with the academic and social achievement of the primary participants

Make myself available for further interviews and discussion should that be required.

I understand that any information I provide is confidential, and that no information that could lead to the identification of any individual will be disclosed in any reports on the project, or to any other party.

I also understand that my participation is voluntary, that I can choose not to participate in the project, and that I can withdraw at any stage of the project without being penalised or disadvantaged in any way.

$\square$ I understand that information gained through this research will be used in the writing of a Masters Thesis and for publication in academic journals and conferences. I also understand that I have the right to check interview notes and challenge the observations of the researcher.

Name:

Signature:

Date: 


\section{Appendix C: Follow up Letter to Participants}

$11^{\text {th }}$ October, 2010

Tena koe,

Firstly, thank you again for your on-going support and participation of this research project. I have completed the first round of interviews and am currently looking at the data and beginning the writing process.

I have enclosed our interview with this cover sheet. When you have a moment, could you please read through the transcript and sign the document anywhere to show that you are happy that what you have read is a true and valid account of our interview. If you wish to comment further or add thoughts that pertain to the interview questions please do.

I would like you to think of a pseudonym which you would be like to be known as in the thesis. I would like the pseudonym to have some sort of significance to you; a role model (that won't identify you or your family). Could you please write the pseudonym down at the bottom of this letter.

The last task I would ask is to indicate a timeframe in December where I can briefly touch base with you again in person. I would like to delve a little deeper into some of the interview questions, or your initial interview responses when we meet again. It will not take very long.

I would appreciate it if you could complete the tasks below and pop this letter and the signed interview back in the envelope and return it to me at school. I am in Room 24 most of the time or you could deliver it to the school office and it will reach me that way. If you wish to discuss any aspects about the research further you can email me: liana.m@xtra.co.nz or phone: 0212992101.

Naku noa, na

Liana MacDonald

1) The pseudonym I would like to be identified as is

2) I am available to be briefly interviewed at the following dates/times in December 


\section{Appendix D: Interview Questions}

How and in what ways do you think that high achieving, academically successful female Māori students succeed in a mainstream schooling environment, and how do participants perceive schooling experiences that encourage/discourage their academic success?

Primary participants

1. Tell me about your experiences of secondary school as a high achieving, female Māori student?

2. What schooling experiences have most supported your achievement? What kinds of support have helped you to achieve at your school (people, subject, friends and family)?

3. What schooling experiences have not supported your achievement?

4. What do you think the ideal teacher would be like?

5. Tell me about your parents' involvement \&/or what support is most helpful to you?

Other participants

1. Tell me about the kinds of experiences that $\underline{\mathrm{xxx}}$ (the name of the Primary participant) has at secondary school as a high achieving, female Māori student?

2. What schooling experiences do you think have most supported the academic achievement of $\underline{\mathrm{xxx}}$ ? What kinds of support have helped $\underline{\mathrm{xxx}}$ achieve at school (people, subject, friends and family)?

3. What school experiences have not supported xxx's achievement?

4. What do you think $\underline{\mathrm{xxx}}$ 's ideal teacher would be like?

5. Tell me how your involvement \&/or support has been helpful to $\underline{\mathrm{xxx}}$ ?

What are multiple identities associated with high achieving Māori girls and those that are particularly related to their academic success?

Primary participants

1. What classrooms in school do you feel more yourself/more comfortable in?

2. What classes do you feel like you need to put on different clothes/act differently in? Can you explain why this is? 
3. Some people would say that in order for a Māori to succeed in a mainstream school (as opposed to a Kura Kaupapa school) they have to give up, or lose elements of their culture to fit in with the dominant culture. What do you say to them?

Other participants

1. What classrooms in school do you think $\underline{\mathrm{xxx}}$ would feel more themselves/more comfortable in?

2. What classes does $\underline{\operatorname{xx}}$ appear to act differently in? Can you explain why this is?

3. Some people would say that in order for a Māori to succeed in a mainstream school (as opposed to a Kura Kaupapa school) they have to give up, or lose elements of their culture to fit in with the dominant culture. What do you say to them?

\section{What tensions do students face in being identified as academically 'high achieving' and 'Māori girls' within a mainstream schooling environment?}

Primary participants

1. How do you think your peers/teacher in your class perceive you?

2. Suppose all your friends were in every class with you. How would this affect your academic success?

3. Do you think that a high achieving and Pākehā girl would find it easier to achieve academically than you? How might their experiences at school differ?

Other participants

1. How do you perceive $\underline{\mathrm{xxx}}$ as a learner at school?

2. Suppose you were in every class with $\underline{\mathrm{xxx}}$. Do you think this would affect their academic success? How?

3. Do you think that a high achieving and Pākehā girl would find it easier to achieve academically than $\underline{\mathrm{xxx}}$ ? How might their experiences at school differ? 